\title{
Analysis of secondary organic aerosol formation and aging using positive matrix factorization of high-resolution aerosol mass spectra: application to the dodecane low-NO $\mathrm{N}_{\mathrm{x}}$ system
}

\author{
J. S. Craven ${ }^{1}$, L. D. Yee $^{2}$, N. L. Ng ${ }^{6}$, M. R. Canagaratna ${ }^{3}$, C. L. Loza ${ }^{1}$, K. A. Schilling ${ }^{1}$, R. L. N. Yatavelli ${ }^{4, *}$, \\ J. A. Thornton ${ }^{4}$, P. J. Ziemann ${ }^{5}$, R. C. Flagan ${ }^{1,2}$, and J. H. Seinfeld ${ }^{1,2}$ \\ ${ }^{1}$ Division of Chemistry and Chemical Engineering, California Institute of Technology, Pasadena, California, USA \\ ${ }^{2}$ Division of Engineering and Applied Science, California Institute of Technology, Pasadena, California, USA \\ ${ }^{3}$ Aerodyne Research, Inc., Billerica, Massachusetts, USA \\ ${ }^{4}$ Department of Atmospheric Sciences, University of Washington, Seattle, Washington, USA \\ ${ }^{5}$ Air Pollution Research Center, Department of Environmental Sciences, and Environmental Toxicology Graduate Program, \\ University of California, Riverside, California, USA \\ ${ }^{6}$ School of Chemical and Biomolecular Engineering and School of Earth and Atmospheric Sciences, Georgia Institute of \\ Technology, Atlanta, Georgia, USA \\ * current address: Cooperative Institute for Research in Environmental Sciences (CIRES), University of Colorado, Boulder, \\ Colorado, USA
}

Correspondence to: J. H. Seinfeld (seinfeld@ caltech.edu)

Received: 7 June 2012 - Published in Atmos. Chem. Phys. Discuss.: 6 July 2012

Revised: 26 October 2012 - Accepted: 4 December 2012 - Published: 17 December 2012

\begin{abstract}
Positive matrix factorization (PMF) of highresolution laboratory chamber aerosol mass spectra is applied for the first time, the results of which are consistent with molecular level MOVI-HRToF-CIMS aerosolphase and CIMS gas-phase measurements. Secondary organic aerosol was generated by photooxidation of dodecane under low- $\mathrm{NO}_{\mathrm{x}}$ conditions in the Caltech environmental chamber. The PMF results exhibit three factors representing a combination of gas-particle partitioning, chemical conversion in the aerosol, and wall deposition. The slope of the measured high-resolution aerosol mass spectrometer (HRToF-AMS) composition data on a Van Krevelen diagram is consistent with that of other low- $\mathrm{NO}_{\mathrm{x}}$ alkane systems in the same $\mathrm{O}$ : $\mathrm{C}$ range. Elemental analysis of the PMF factor mass spectral profiles elucidates the combinations of functionality that contribute to the slope on the Van Krevelen diagram.
\end{abstract}

\section{Introduction}

The processes by which the atmospheric oxidation of volatile organic compounds (VOCs) leads to low volatility products that partition into the aerosol phase, forming Secondary Organic Aerosol (SOA), are complex and not thoroughly understood. Gas-phase oxidation processes are key in SOA formation, but there is increasing evidence that chemistry occurring in the particle phase, as well, may be important in producing the low-volatility, oxygenated compounds that characterize SOA. Laboratory chamber studies are essential to understand the lifecycle of organics involved in the formation of SOA. In such chamber experiments, measurements of both gas- and particle-phase chemical composition provide a window into the complex chemistry of SOA formation. While measurement of the complete suite of compounds involved in SOA formation is generally not feasible, key observations can provide considerable insight into the nature of the multi-generation gas-phase oxidation that characterizes SOA formation. High-Resolution Time-of-Flight

Published by Copernicus Publications on behalf of the European Geosciences Union. 
Aerosol Mass Spectrometer (HR-ToF-AMS) measurements of aerosol composition enable derivation of a number of key SOA properties; these include the atomic oxygen-to-carbon and hydrogen-to-carbon ratios $(\mathrm{O}: \mathrm{C}$ and $\mathrm{H}: \mathrm{C})$, from which one can infer the overall oxidation state of the aerosol. The full HR-ToF-AMS spectrum, over the course of SOA formation and evolution, comprises a large number of massto-charge ratios $(m / z)$, which contain time-dependent information on the overall processes occurring. Positive Matrix Factorization (PMF) has proved to be a powerful procedure for analyzing HR-ToF-AMS spectra in terms of the evolution of major mass spectral factors (Lanz et al., 2007; Ulbrich et al., 2009; Aiken et al., 2009; Ng et al., 2010; Hersey et al., 2011; Fry et al., 2011). The factor profile extracts the contributions from a number of masses that are co-correlated, providing information on the time evolution of the aerosol composition that is not immediately evident from the complex aerosol spectrum. We present here the first application of PMF to HR-ToF-AMS spectra obtained in a laboratory chamber investigation of SOA formation.

The present study is part of a comprehensive investigation of SOA formation from large alkanes. Historically, alkanes have been considered a significant atmospheric component of the unresolved complex mixture (UCM) of organics (Schauer et al., 2001, 2002). With the advent of a recently developed soft ionization gas chromatography technique, the unresolved complex mixture has been characterized at the molecular level to contain $n$-alkanes, cycloalkanes, bicycloalkanes, tricycloalkanes, and steranes (Isaacman et al., 2012). Pye and Pouliot (2012) predict from the Community Multiscale Air Quality (CMAQ) model the SOA yield from alkanes and PAHs to be 20 to $30 \%$ of that from anthropogenic hydrocarbons. In particular, the linear alkane is predicted to dominate the SOA yield for the $\mathrm{C}_{12}$ alkanes. This first phase of the comprehensive investigation of alkanes focuses on high-resolution HR-ToF-AMS spectra of dodecane $\left(\mathrm{C}_{12} \mathrm{H}_{26}\right) \mathrm{SOA}$. In conjunction with Chemical Ionization Mass Spectrometer (CIMS) measurements, and MicroOrifice Volatilization Impactor Coupled to a Chemical Ionization Mass Spectrometer (MOVI-HRToF-CIMS), the application of PMF provides insight into the multi-generational and multi-phase processes involved in SOA formation and aging.

\section{Experimental}

Experiments were carried out in the Caltech environmental chamber facility, which is comprised of dual $28 \mathrm{~m}^{3}$ teflon chambers (Table 1, Cocker et al., 2001). Experiments were carried out in a low- $\mathrm{NO}_{\mathrm{x}}$ environment with hydrogen peroxide $\left(\mathrm{H}_{2} \mathrm{O}_{2}\right)$ photolysis as the $\mathrm{OH}$ source. For each experiment, $280 \mu \mathrm{l}$ of $50 \%$ wt aqueous $\mathrm{H}_{2} \mathrm{O}_{2}$ solution was evaporated into the chamber, followed by atomization of $0.015 \mathrm{M}$ aqueous ammonium sulfate (AS) solution for seed particles, which were subsequently dried. Finally, the specific volume of liquid dodecane necessary to achieve the desired gasphase concentration was evaporated into the chamber. The oxidant, seed, and hydrocarbon mixed for $1 \mathrm{~h}$ prior to irradiation.

\subsection{High-resolution time-of-flight aerosol mass spectrometer}

In the Aerodyne high-resolution time-of-flight aerosol mass spectrometer (HR-ToF-AMS), aerosol is sampled at atmospheric pressure through an aerodynamic lens into a particle time-of-flight chamber, at the end of which the particles impact a $600^{\circ} \mathrm{C}$ heater and $70 \mathrm{eV}$ filament assembly where they are vaporized and ionized. The aerosol ion fragments are then orthogonally extracted into the ion time-of-flight chamber where they are sampled in either V (higher signal) or $\mathrm{W}$ (higher resolution) mode. For these experiments, both modes were utilized at a 1 min sequential sampling rate. The V-mode was utilized for PMF analysis, as the higher $m / z$ values exhibit a more favorable signal-to-noise ratio; the $\mathrm{W}$-mode was used for ion identification, clarification, and elemental analysis. The V-mode and $\mathrm{W}$-mode can be set to measure bulk aerosol composition in which all of the particles within the transmission of the instrument (60-600 nm with $100 \%$ transmission efficiency) are measured. This is commonly referred to as mass spec.-mode (MS-mode). The HR-ToF-AMS can also measure size-resolved chemistry by employing the particle timeof-flight-mode (PTOF-mode) in which the aerosol beam is chopped in the particle time-of-flight chamber and single particles are sized and sampled. All HR-ToF-AMS data were processed with "Squirrel", the ToF-AMS Unit Resolution Analysis Toolkit (http://cires.colorado.edu/jimenez-group/ ToFAMSResources/ToFSoftware/index.html), in Igor Pro Version 6.22A (Wavemetrics, Lake Oswego, OR). Adjustments to the fragmentation table were made to correct for air interferences based on measurements made at the beginning of each experiment with a particle filter in-line with the chamber sample line and the HR-ToF-AMS (Allan et al., 2004). The ToF-AMS High Resolution Analysis software tool PIKA (Peak Integration by Key Analysis) was employed for high-resolution analysis (DeCarlo et al., 2006). Elemental ratios were calculated using the technique outlined by Aiken et al. (2008) and Chhabra et al. (2010).

\subsection{Chemical Ionization Mass Spectrometer}

A Chemical Ionization Mass Spectrometer (CIMS) was employed for the measurement of gas-phase photooxidation products, including key intermediates contributing to the particle phase. The CIMS consists of a Varian 1200 triple quadrupole mass spectrometer that has been modified to accommodate a custom ionization region. Sample air from the environmental chamber flows at $190 \mathrm{sccm}$ into a glass flow 
Table 1. Experimental conditions for dodecane low- $\mathrm{NO}_{\mathrm{x}}$ photooxidation.

\begin{tabular}{cccccc}
\hline Exp \# & $\begin{array}{c}\text { duration } \\
(\mathrm{h})\end{array}$ & $\begin{array}{c}\text { initial hydrocarbon conc. } \\
(\mathrm{ppb})\end{array}$ & seed type & $\begin{array}{c}\text { initial seed volume } \\
\left(\mu \mathrm{m}^{3} \mathrm{~cm}^{-3}\right)\end{array}$ & \begin{tabular}{l} 
HR-ToF-AMS mode \\
\hline 1
\end{tabular} \\
\hline 18 & 34 & AS & 9.1 & MS-mode, (V and W) \\
2 & 34 & 34 & AS & 11.4 & (MS-mode (V and W) \\
3 & 18 & 33 & AS & 12.0 & MS-mode (V and W) \\
4 & 18 & 50 & AS & 14.1 & MS-mode (V and W), PTOF-mode (V) \\
5 & 18 & 300 & AS & 34.7 & \\
\hline
\end{tabular}

tube, where it is diluted by a factor of nine with $\mathrm{N}_{2}$ gas. It then enters the chemical ionization region. The CIMS uses $\mathrm{CF}_{3} \mathrm{OOCF}_{3}$ reagent gas, generating cluster products at $\left[\mathrm{X} . \mathrm{CF}_{3} \mathrm{O}\right]^{-}$and fluoride transfer products at $[\mathrm{X} . \mathrm{F}]^{-}$, where $\mathrm{X}$ is the analyte. Hydroperoxide-containing species are detected as a cluster product, and strongly acidic species are primarily detected as the transfer product. More weakly acidic species can be detected as both a cluster and transfer product. In these experiments, such products were tracked with the CIMS as discussed previously (Yee et al., 2012). Additional details of the instrument and its general operation have been described elsewhere (St. Clair et al., 2010; Paulot et al., 2009; Crounse et al., 2006).

\subsection{Micro-orifice volatilization impactor coupled to a high-resolution time-of-flight chemical ionization mass spectrometer}

A micro-orifice volatilization impactor coupled to a highresolution time-of-flight chemical-ionization mass spectrometer (MOVI-HRToF-CIMS) was employed. Analysis in the MOVI-HRToF-CIMS is a two-step cycle in which (i) gasphase compounds are measured by the high-resolution TOFMS while aerosols are collected, and (ii) collected aerosols are then thermally vaporized with composition measured by the spectrometer. Chemical ionization (CI) preserves the parent ion in most cases, which, when combined with a high-resolution TOF analyzer, allows determination of the elemental composition of the molecular ions in the mass range of $17-550 \mathrm{~m} / \mathrm{z}$ with a mass resolution of 4500 for mass to charge $>100$ (Yatavelli and Thornton, 2010; Yatavelli et al., 2012).

\subsection{Positive Matrix Factorization (PMF)}

Positive Matrix Factorization (PMF) has emerged as a powerful technique for source apportionment of HR-ToF-AMS measurements of ambient aerosol (Paatero and Tapper, 1994; Jimenez et al., 2009; Lanz et al., 2007; Ulbrich et al., 2009; Aiken et al., 2009; Hersey et al., 2011; $\mathrm{Ng}$ et al., 2010; Allan, 2003; Zhang et al., 2011). Here, the application of PMF to HR-ToF-AMS spectra to investigate SOA formation in a laboratory chamber is reported for the first time. The factors are groups of ions (or fractions of ions) that vary together in time. For chamber experiments, this variation could result from processes such as gas-particle partitioning, chemical conversion in the aerosol, or wall loss of either individual molecules, or more likely a group of molecules with similar chemical character, such as the gasphase products from a specific generation of gas-phase oxidation. Gas-phase measurements support and the dodecane low- $\mathrm{NO}_{\mathrm{x}}$ mechanism predicts the multi-generation production of increasingly oxidized gas-phase products, which are expected to condense at different times. The AMS-PMF time series results are compared with molecular level detail of the CIMS gas-phase and MOVI-HRToF-CIMS aerosolphase measurements, linking the HR-ToF-AMS high timeresolution electron impact ion information to the complex aerosol molecular level composition. The PMF results are explored using the PMF Evaluation Tool Version 2.04 in Igor Pro (http://cires.colorado.edu/jimenez-group/ wiki/index.php/PMF-AMS_Analysis_Guide, Ulbrich et al., 2009). The details of implementing PMF are given in the Appendix A.

\section{Results}

SOA formation and aging comprise a number of atmospheric processes: (1) gas-phase reactions involving the primary organic and its oxidation products that involve functionalization and fragmentation; (2) gas-particle partitioning of lower volatility products; (3) chemical reactions in the aerosol phase that can lead to even lower volatility compounds or, in some cases, fragmentation and return to the gas phase. In interpreting the results of laboratory chamber experiments, one must also consider the effect of deposition of gases and particles to the chamber walls. In the present study we seek, via a combination of HR-ToF-AMS and CIMS measurements, to evaluate both gas- and particle-phase routes to formation of oxidized compounds.

\subsection{Elemental ratios}

Figure 1 shows the evolution of total organic aerosol mass during the longer experiment (Table 1). The $\mathrm{O}: \mathrm{C}$ and $\mathrm{H}: \mathrm{C}$ elemental ratios of the aerosol provide information on the bulk chemical evolution over the course of the experiment. 


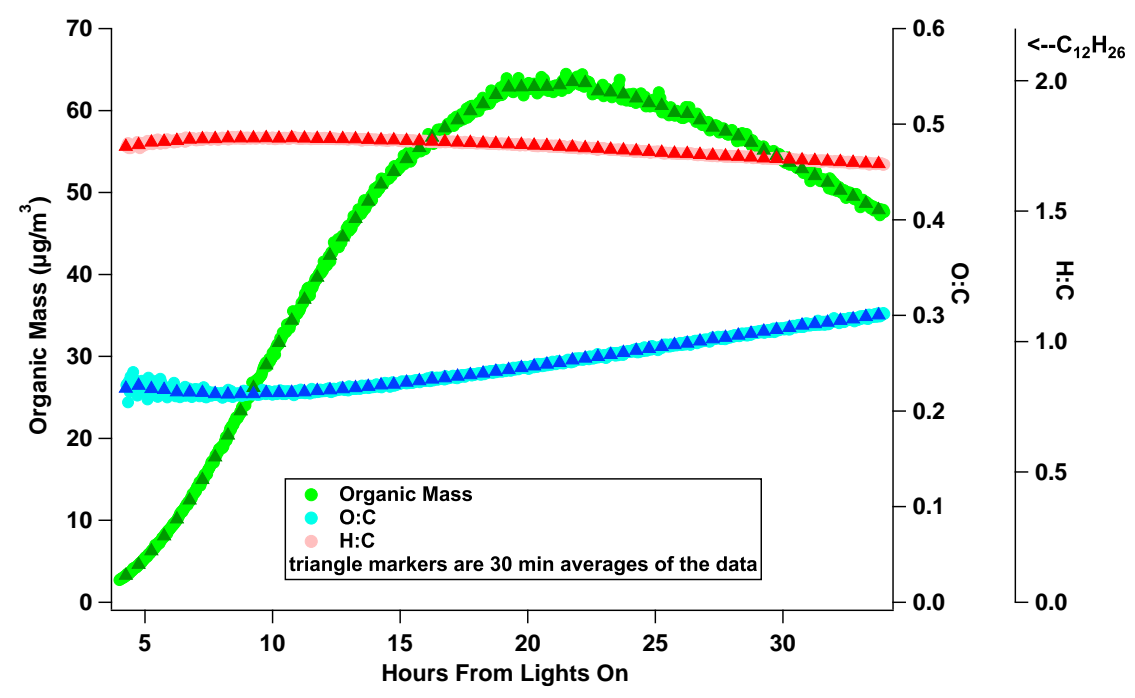

Fig. 1. Total organic aerosol mass and $\mathrm{O}: \mathrm{C}$ and $\mathrm{H}: \mathrm{C}$ elemental ratios for experiment 2 . The $\mathrm{C}_{2} \mathrm{H}_{4}^{+}$ion has been removed from the mass spectra due to its interference with the large signal from the $\mathrm{N}_{2}^{+}$ion. The triangles are 30 min averages of the data.

The first reliable $\mathrm{O}: \mathrm{C}$ measurement yields a value near 0.22 , which is consistent with the predicted early aerosol product, the $\mathrm{C}_{12}$ carbonyl hydroperoxide (product formula of $\mathrm{C}_{12} \mathrm{H}_{24} \mathrm{O}_{3}, \mathrm{O}: \mathrm{C}$ of 0.25 ). Upon further $\mathrm{OH}$ exposure, the $\mathrm{O}: \mathrm{C}$ ratio grows to about 0.3 . The $\mathrm{H}: \mathrm{C}$ ratio is initially at 1.7 , reflecting the oxidized nature of the aerosol composition at a relatively early stage of formation. The $\mathrm{H}: \mathrm{C}$ ratio then increases after early growth to 1.79 and then decreases to 1.69 at $34 \mathrm{~h}$. Dodecane itself has an $\mathrm{H}: \mathrm{C}$ of 2.17 and an $\mathrm{O}: \mathrm{C}$ of 0 , so the initially high $\mathrm{H}: \mathrm{C}$ and low $\mathrm{O}: \mathrm{C}$ reflect the early oxidation stage of aerosol. The $\mathrm{C}_{2} \mathrm{H}_{4}^{+}$ion was removed from the mass spectra owing to large interference with the $\mathrm{N}_{2}^{+}$ion, but with little effect on the absolute value and time trend of the elemental ratios. Individual high resolution ions provide further information on those masses in the spectrum that are driving the evolution of the aerosol chemical composition.

\subsection{High-resolution ion analysis}

The higher mass ions $(>m / z, 100)$ in the HR-ToFAMS spectrum provide key information regarding the lowvolatility SOA constituents. Owing to the fragmentation caused by electron impact ionization, numerous ion combinations contribute to each nominal mass; the larger the mass, the greater the potential information regarding molecular detail, but the greater challenge in extracting that information. An explicit chemical mechanism of dodecane oxidation is critical in identifying individual ions, as well as patterns in the HR-ToF-AMS spectrum. A simplified schematic of the low- $\mathrm{NO}_{\mathrm{x}}$ mechanism presented by Yee et al. (2012) is shown in Fig. 2.
At early growth, $m / z 183$ and $m / z 215$ dominate the signal for $m / z>100$ (Figs. 3 and 4). At the outset, the only apparent ion at $m / z 183$ is $\mathrm{C}_{12} \mathrm{H}_{23} \mathrm{O}^{+}$, but by the end of oxidation, $\mathrm{C}_{10} \mathrm{H}_{15} \mathrm{O}_{3}^{+}$has clearly grown in as a "left-side" neighbor to the original ion. This same type of behavior occurs for $m / z 215$ and, indeed, for almost all of the other masses in the spectrum. These developing patterns allow for a systematic identification of the ions at each mass. In each case, the later neighboring ion(s) have fewer carbons and more oxygens, as expected from continuous multi-generation oxidation. The unit mass resolution signals of $m / z 183$ and $m / z 215$, shown in Figs. 3 and 4, emphasize the difference in information between the unit mass and high-resolution analysis. The high resolution ions well past $m / z, 100$ provide ion trend information (see Sect. 3.3), even if these ions do not influence the overall $\mathrm{H}: \mathrm{C}$ and $\mathrm{O}: \mathrm{C}$ ratios owing to small mass contributions.

\subsection{Varying time trends for $\mathrm{C}_{12}$ ion fragments}

The ions at higher $m / z$ provide unique time traces from which inferences about the aerosol composition can be drawn. For example, the time series of $\mathrm{C}_{12}$ fragments in Fig. 5 shows distinct maxima during the course of the experiment. Since the parent hydrocarbon is a $\mathrm{C}_{12}$ molecule, the fragments shown in Fig. 5 are close to molecular level detail. The steady increase in signal of the less oxidized ion $\mathrm{C}_{12} \mathrm{H}_{23} \mathrm{O}^{+}$at $m / z$ 183, followed by the increase of $\mathrm{C}_{12} \mathrm{H}_{21} \mathrm{O}_{2}^{+}$at $m / z$ 197, and then $\mathrm{C}_{12} \mathrm{H}_{19} \mathrm{O}_{3}^{+}$at $m / z 211$ reflect the incorporation of increasingly oxidized products to the aerosol. The processes by which each ion reaches a maximum and then decreases are more challenging to infer. Deposition of aerosol to the chamber walls will cause the ion 

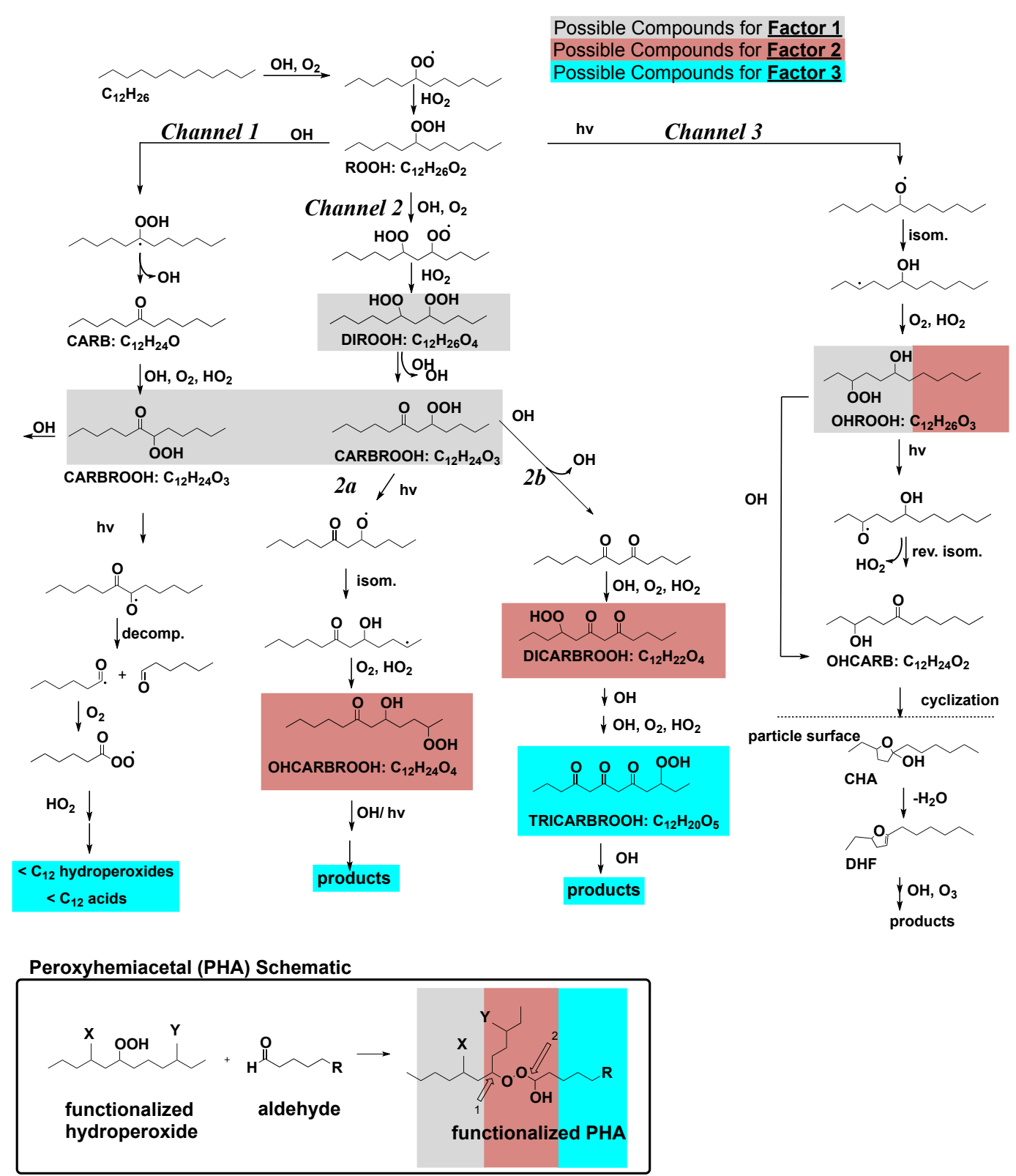

Fig. 2. Simplified chemical mechanism for dodecane photooxidation under low- $\mathrm{NO}_{\mathrm{x}}$, adapted from Yee et al. (2012). Shaded portions of the mechanisms are possible assignments for the PMF factors 1, 2 and 3, as discussed in Sects. 3.4 and 3.5.

signals to decrease (Sect. 3.6). A decreasing trend could also be the result of partitioning of products back to the gasphase as their gas-phase equivalent reacts. Then, upon further oxidation in the gas-phase, the product re-condenses as a more oxidized species. Chemical conversion of the condensed products would provide another explanation for some ions to be decreasing, at the same time other ions are increasing. In electron impact ionization a particular ion fragment can be produced from two different compounds. This effect is magnified in the smaller $m / z$ 's, for example, the $\mathrm{C}_{2} \mathrm{H}_{3}^{+}$ion at $m / z 27$, which is dominant throughout the entire experiment and a common fragment for alkyl molecules.

The ions identified in the HR-ToF-AMS spectra are a linear combination of the molecules in the aerosol; positive matrix factorization is well suited for long-duration chamber experiments, especially with ions that have unique time trends. The PMF results are an attempt to rebuild the molecular trend information that is lost from electron impact ionization in the HR-ToF-AMS. The less harsh ionization methods of both the heating mode of the MOVI-HRToF-CIMS and gas-phase measurements from the CIMS provide molecular 


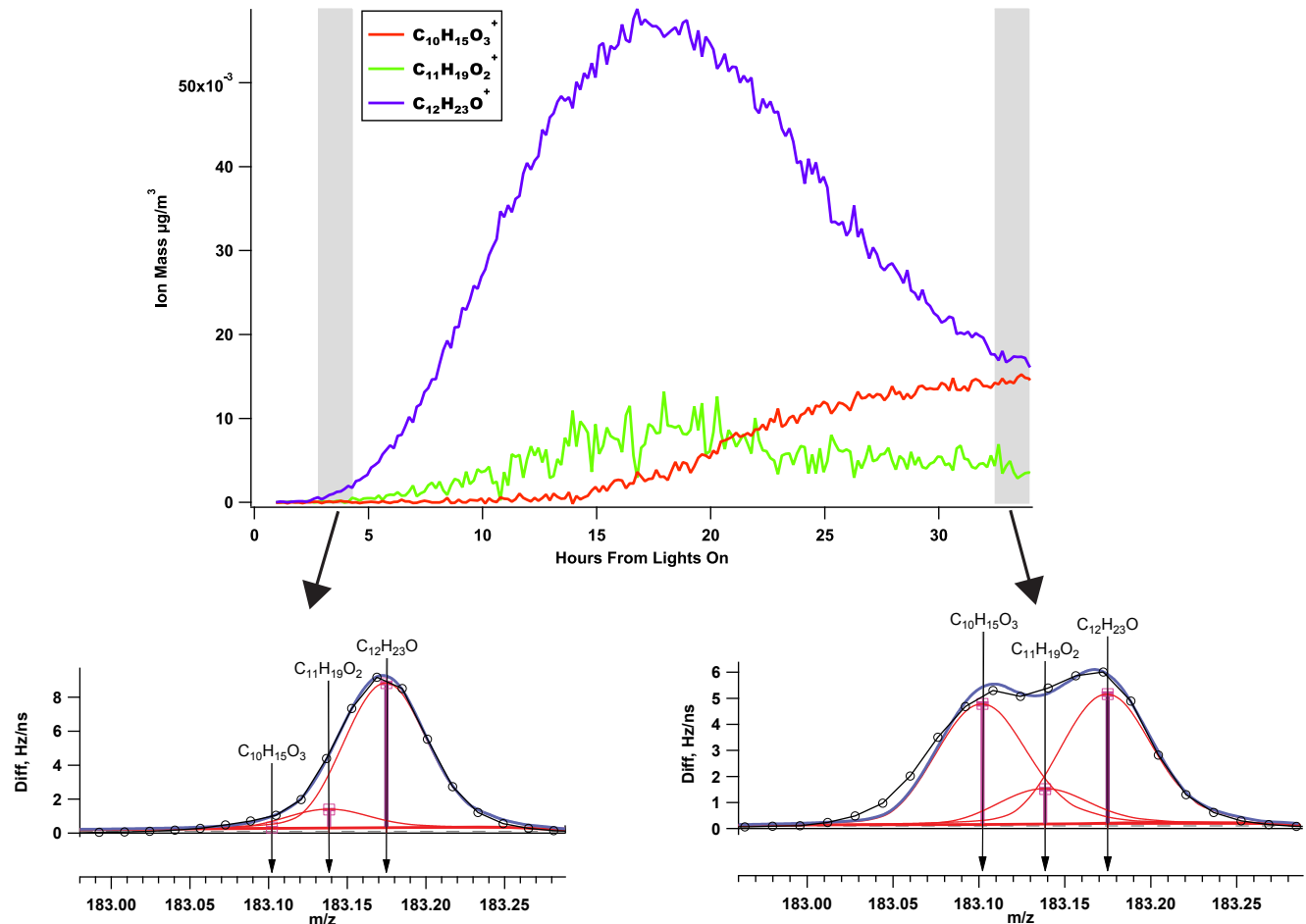

Fig. 3. Time series of ions and the raw data for "early growth" and "most oxidized growth" for $m / z 183$.

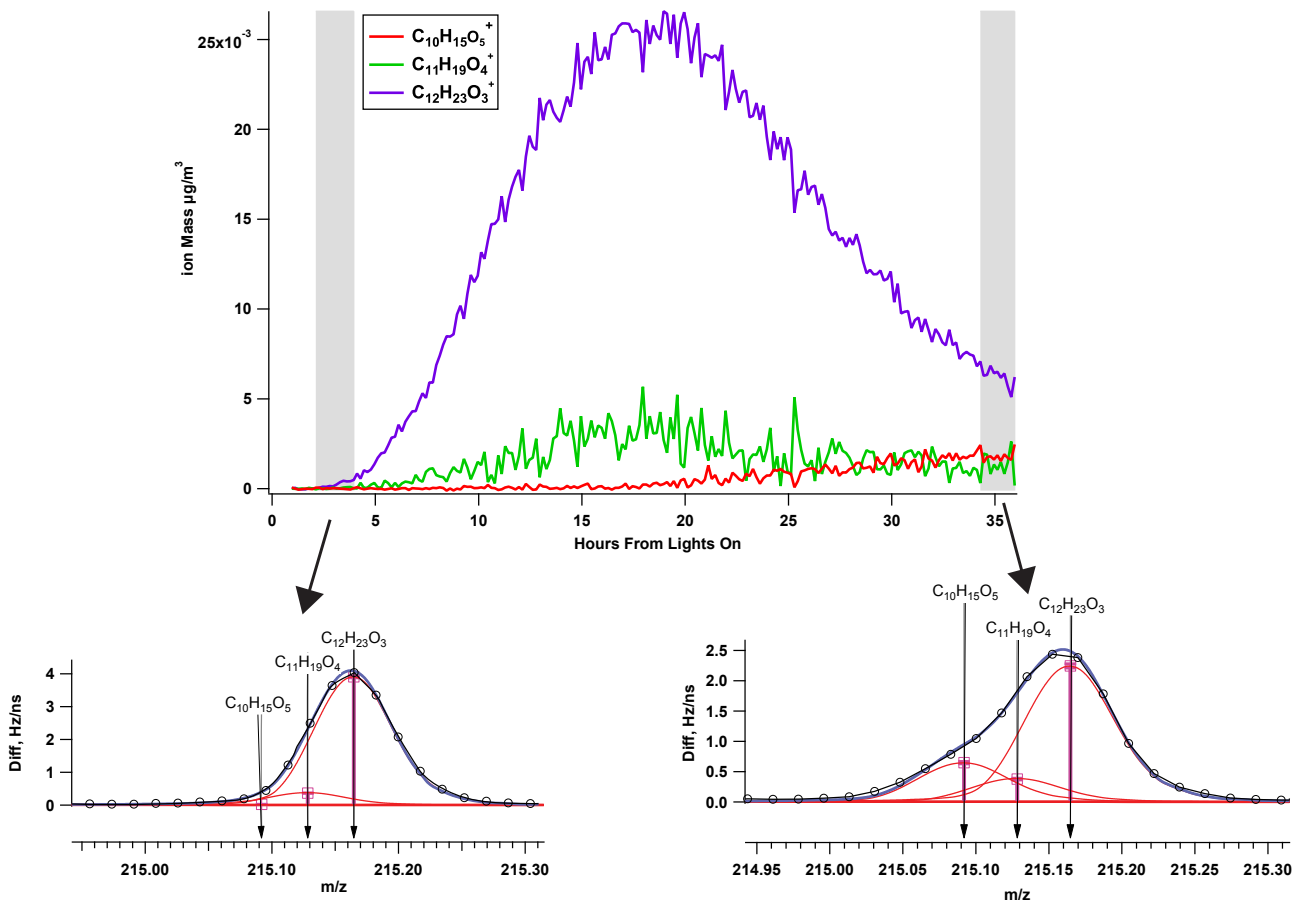

Fig. 4. Time series of ions and the raw data for "early growth" and "most oxidized growth" for $m / z 215$. 


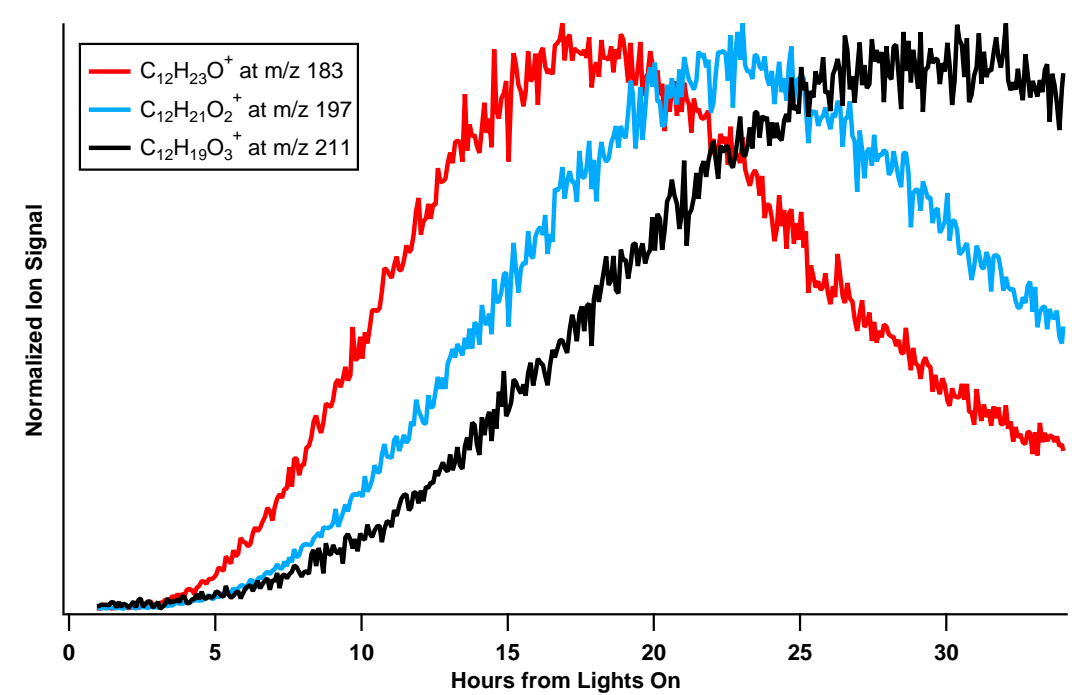

Fig. 5. $\mathrm{C}_{12}$ backbone ions with varying contributions of oxygen have distinct time trends over the duration of the experiment.

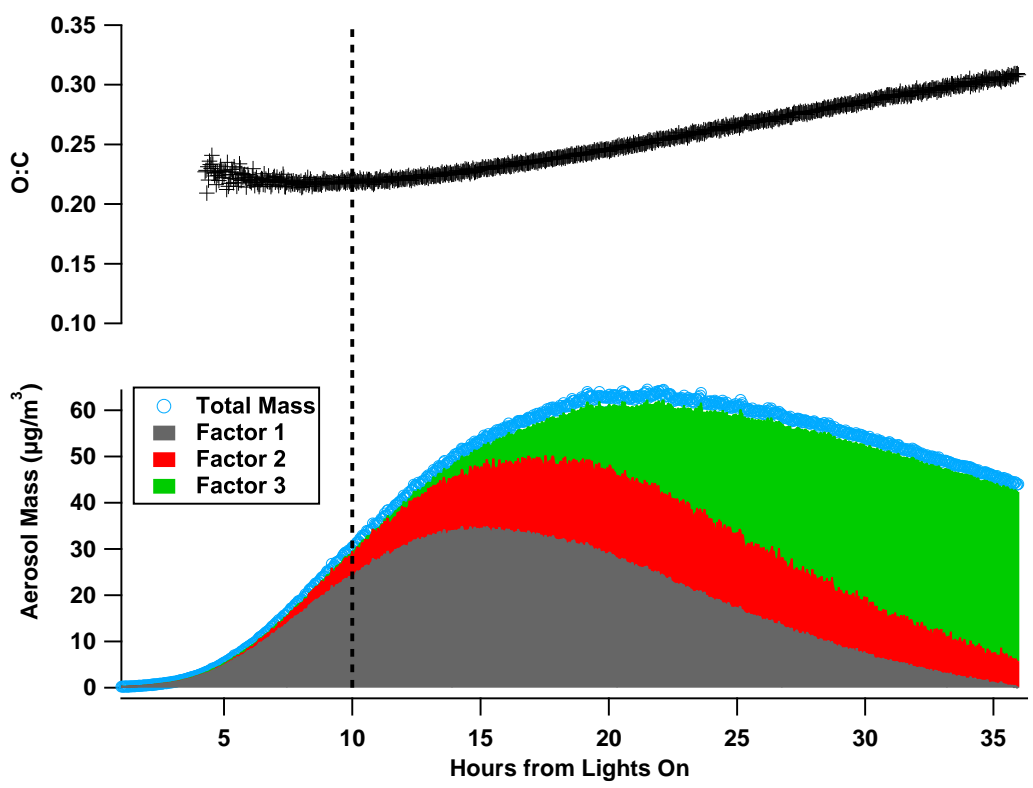

Fig. 6. Three-factor PMF solution, total organic mass, and $\mathrm{O}: \mathrm{C}$ ratio. The dashed line denotes the point at which factor 3 grows in and the $\mathrm{O}: \mathrm{C}$ begins to rise appreciably.

level information that the HR-ToF-AMS is unable to obtain, but to which the PMF results show similarity. From this comparison, molecular information can be inferred about the HRToF-AMS spectra, and how compounds fragment in the HRToF-AMS. Moreover, PMF results can be applied to obtain insight into the partitioning of the populations of oxidized molecules and the aerosol composition that evolves with continued oxidation.

\subsection{Three-factor PMF solution}

The PMF results for low- $\mathrm{NO}_{\mathrm{x}} \mathrm{SOA}$ formation from dodecane oxidation exhibit three distinct time traces with their correlating factor mass spectral profiles (Figs. 6 and 7) . The three factor time series, shown in Fig. 6, are overlaid with the total organic loading to emphasize the relationship of each factor to the total SOA mass. The $\mathrm{O}: \mathrm{C}$ ratio traces the overall oxidation state in the aerosol, and the PMF factors help explain that behavior. Factor 1, in grey, is dominant in the early aerosol growth and contains the least oxidized ions 


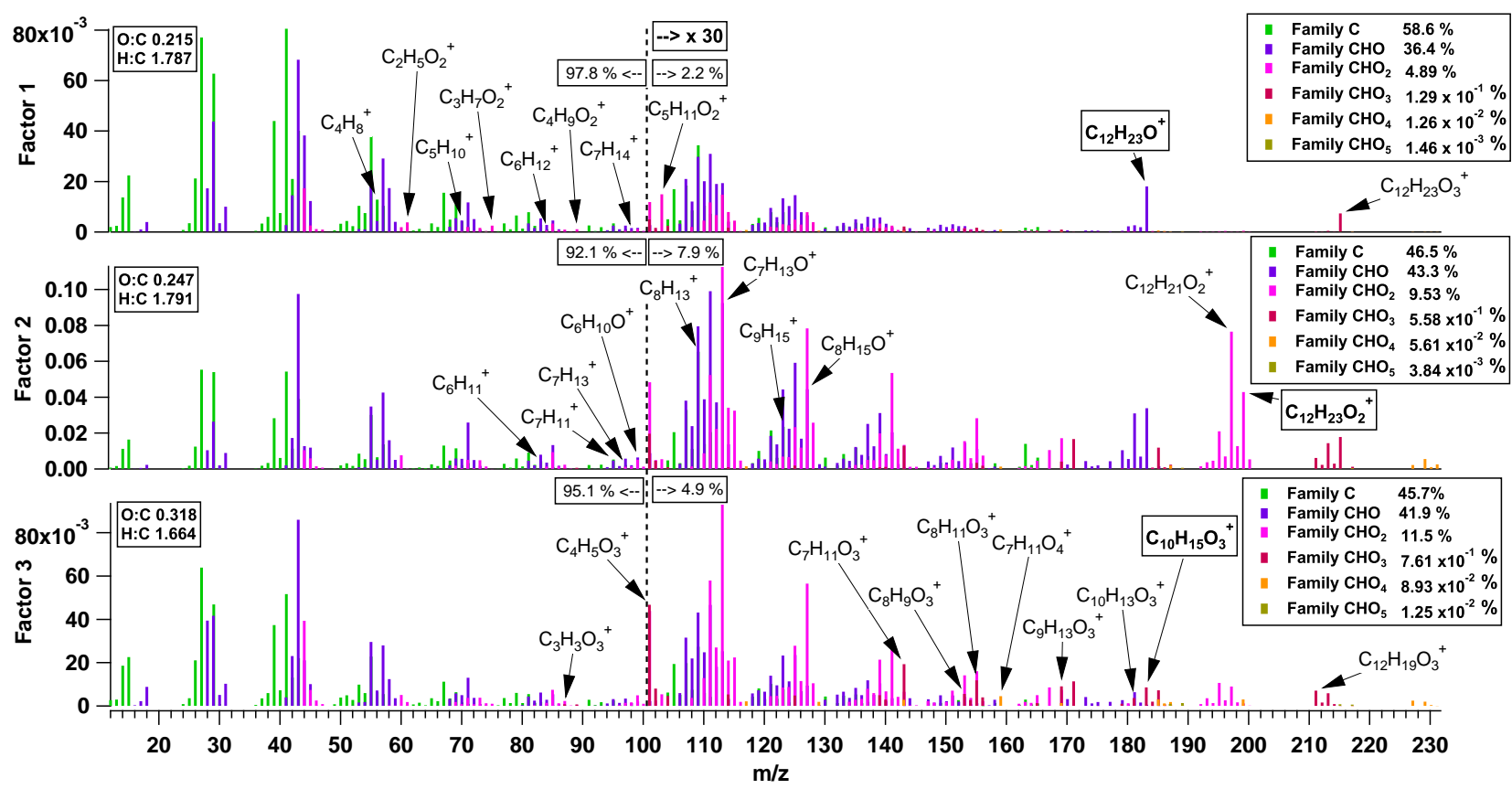

Fig. 7. The 3-factor mass spectra profiles in terms of their families. The ions past $m / z 100$ are multiplied by 30 to amplify signal strength.

(has the highest $\mathrm{H}: \mathrm{C}$ ratio) of the factors. Factor 2 grows in next, peaks after factor 1, and then decreases. Factor 3 contains the highest contribution to the $\mathrm{CO}^{+}$and $\mathrm{CO}_{2}^{+}$ions and other $\mathrm{O}_{2}, \mathrm{O}_{3}, \mathrm{O}_{4}$, and $\mathrm{O}_{5}$ - containing ions, explaining the steady increase in $\mathrm{O}: \mathrm{C}$ over the course of the experiment. The $\mathrm{CO}_{2}^{+}$ion is the tracer for carboxylic acid in the HR-ToFAMS (Aiken et al., 2008), which could explain the increase in $\mathrm{O}: \mathrm{C}$; however, the existence of the $>2$ oxygen ion fragments indicates the $\mathrm{O}: \mathrm{C}$ ratio increase could also be due to highly functionalized compounds, and not solely carboxylic acids, an observation supported by the chemical mechanism (Fig. 2) and the Van Krevelen Diagram (Sect. 3.7).

The mass spectral profiles of the factors are presented in Fig. 7, in which ions with different oxygen contents (different ion families) are highlighted by different colors. The mass percentage of each family to the total factor is presented in each factor's legend. Each factor profile has distinct, unique masses in the $>m / z 100$ range. While it is difficult to identify an ion unique to one factor, certain ions have a higher contribution to one factor than another. Pearson's $r$ correlation of each ion in the spectrum to each factor time series was used to identify which unique ions contribute the most to each factor. The 10 ions with the highest correlation in time with the factor profiles are tagged in the figure, with the top ion surrounded by a box. These are also listed in Table 3 . The time trends of the top 3 ions correlating with each factor are displayed in Fig. 8. These ions provide the basis for identifying HR-ToF-AMS tracer ions for different generations of oxidation products. The interpretation of these factor time series and mass spectral profiles is aided by a chemical mech- anism of dodecane oxidation, as well as comparison of time series to CIMS and MOVI-HRToF-CIMS data and individual HR-ToF-AMS ions.

\subsection{Chemical interpretation of PMF solution}

Factor 1 mass spectra and time series correlations with CIMS (Fig. 10) and MOVI-HRToF-CIMS (Fig. 11) ion time traces suggest that factor 1 could be $\mathrm{C}_{12}$ carbonyl hydroperoxide or $\mathrm{C}_{12}$ dihydroperoxide gas-to-particle partitioning (CARBROOH or DIROOH, Fig. 2, see grey shaded box) and possibly peroxyhemiacetal formation (see inset from Fig. 2). A $\mathrm{C}_{18} \mathrm{H}_{38}$ low- $\mathrm{NO}_{\mathrm{x}}$ photooxidation experiment was carried out to produce a hydroperoxide standard and to understand the hydroperoxide fragmentation pattern in the HR-ToF-AMS (Fig. 9 and Table 4). The first product from $\mathrm{C}_{18} \mathrm{H}_{38}$ low- $\mathrm{NO}_{\mathrm{x}}$ photooxidation is the hydroperoxide, which because of its long carbon chain, is expected to condense immediately onto the aerosol. Removal of $\mathrm{HO}_{2}$ from the $\mathrm{C}_{18}$ hydroperoxide is supported by the $\mathrm{C}_{18} \mathrm{H}_{37}^{+}$ion in the HR-ToF-AMS spectrum; this ion is considered a tracer for the $\mathrm{C}_{18}$ hydroperoxide. Fraser et al. (1970) also saw alkyl ions with $70 \mathrm{eV}$ electronic impact ionization mass spectrometry measurements of alkyl hydroperoxides and attributed these peaks to $\mathrm{HO}_{2}$ elimination from the hydroperoxide. The $\mathrm{C}_{3} \mathrm{H}_{7} \mathrm{O}_{2}^{+}$ion is also considered to be a tracer for the hydroperoxide-like compound since it has the highest percent difference between the $\mathrm{C}_{18} \mathrm{H}_{38}$ condensation spectrum before irradiation and the mass spectrum immediately after irradiation.

For dodecane, we do not expect the $\mathrm{C}_{12}$ hydroperoxide to partition to the particle phase, but we do expect the $\mathrm{C}_{12}$ 

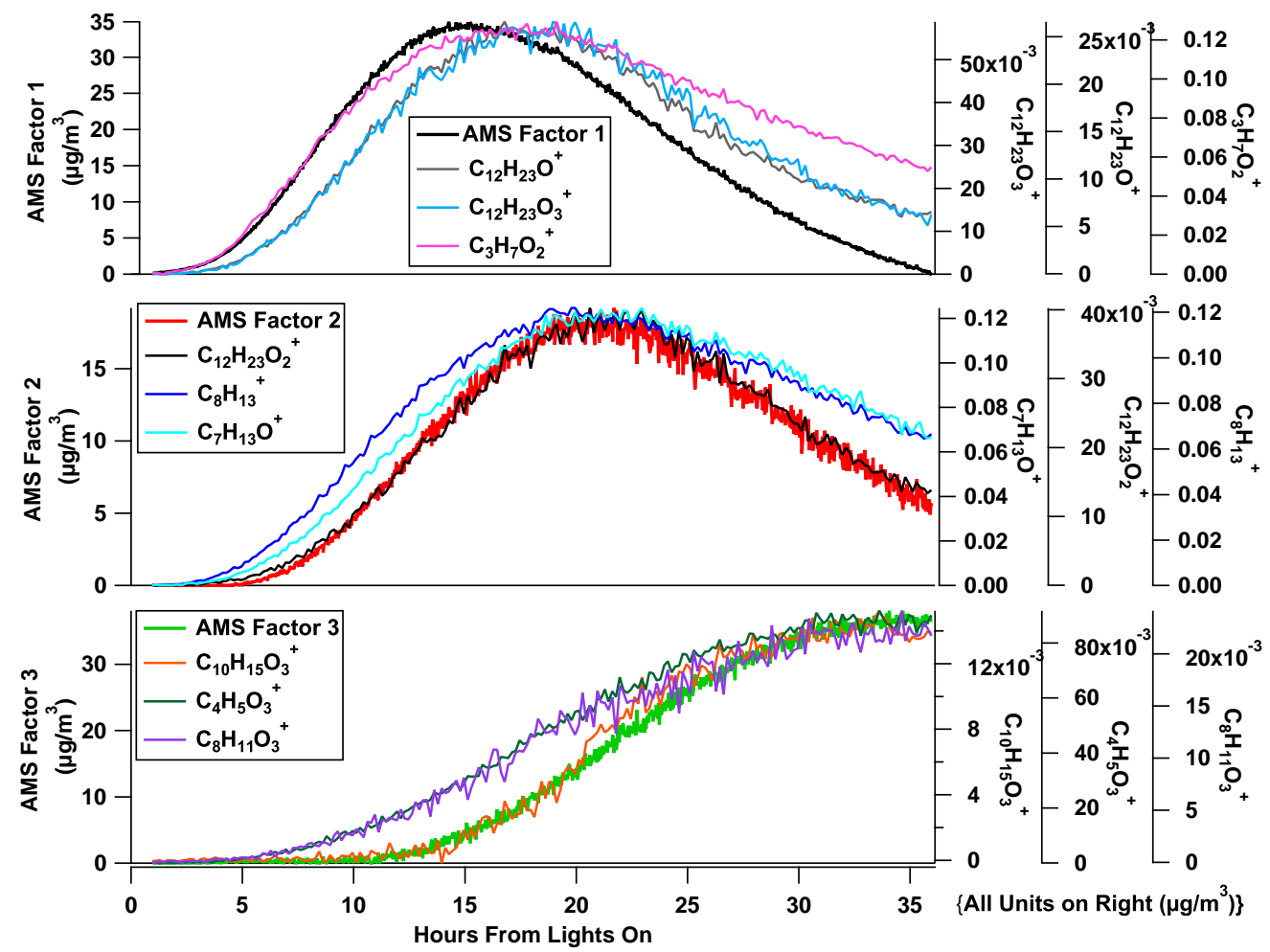

Fig. 8. Factor time series with the top three highest Pearson's r correlating HR-ToF-AMS ions.

Table 2. Ion fragments.

\begin{tabular}{lll}
\hline$m / z$ & Ion & possible identification \\
\hline 169 & $\mathrm{C}_{12} \mathrm{H}_{25}+$ & hydroperoxide, hydroperoxide-peroxyhemiacetal \\
201 & $\mathrm{C}_{12} \mathrm{H}_{25} \mathrm{O}_{2}^{+}$ & hydroperoxide-peroxyhemiacetal \\
\hline 185 & $\mathrm{C}_{12} \mathrm{H}_{25} \mathrm{O}^{+}$ & hydroxy hydroperoxide, hydroxy hydroperoxide-peroxyhemiacetal \\
217 & $\mathrm{C}_{12} \mathrm{H}_{25} \mathrm{O}_{3}^{+}$ & hydroxy hydroperoxide-peroxyhemiacetal \\
\hline 183 & $\mathrm{C}_{12} \mathrm{H}_{23} \mathrm{O}^{+}$ & carbonyl hydroperoxide, carbonyl hydroperoxide-peroxyhemiacetal \\
215 & $\mathrm{C}_{12} \mathrm{H}_{23} \mathrm{O}_{3}^{+}$ & carbonyl hydroperoxide-peroxyhemiacetal \\
\hline 197 & $\mathrm{C}_{12} \mathrm{H}_{21} \mathrm{O}_{2}^{+}$ & dicarbonyl hydroperoxide, dicarbonyl hydroperoxide-peroxyhemiacetal \\
229 & $\mathrm{C}_{12} \mathrm{H}_{21} \mathrm{O}_{4}^{+}$ & dicarbonyl hydroperoxide-peroxyhemiacetal \\
\hline 199 & $\mathrm{C}_{12} \mathrm{H}_{23} \mathrm{O}_{2}^{+}$ & hydroxy carbonyl hydroperoxide, hydroxy carbonyl hydroperoxide-peroxyhemiacetal \\
231 & $\mathrm{C}_{12} \mathrm{H}_{23} \mathrm{O}_{4}^{+}$ & hydroxy carbonyl hydroperoxide-peroxyhemiacetal \\
\hline 211 & $\mathrm{C}_{12} \mathrm{H}_{19} \mathrm{O}_{3}^{+}$ & tricarbonyl hydroperoxide, tricarbonyl hydroperoxide-peroxyhemiacetal \\
243 & $\mathrm{C}_{12} \mathrm{H}_{19} \mathrm{O}_{5}^{+}$ & tricarbonyl hydroperoxide-peroxyhemiacetal \\
\hline
\end{tabular}

carbonyl hydroperoxide to partition (Yee et al., 2012). The presence of ion fragment $\mathrm{C}_{12} \mathrm{H}_{23} \mathrm{O}^{+}$at $m / z 183$ supports this explanation (Fig. 3). The $\mathrm{C}_{12} \mathrm{H}_{23} \mathrm{O}_{3}{ }^{+}$ion at $\mathrm{m} / z 215$ (a $32 \mathrm{~m} / z$ and $\mathrm{O}_{2}^{+}$difference from the carbonyl hydroperoxide ion) trends with the $\mathrm{C}_{12} \mathrm{H}_{23} \mathrm{O}_{3}^{+}$ion with a Pearson's $\mathrm{r}$ of 0.986 and is the ion with the highest correlation in the entire spectrum to $\mathrm{C}_{12} \mathrm{H}_{23} \mathrm{O}^{+}$. A possible assignment of $\mathrm{C}_{12} \mathrm{H}_{23} \mathrm{O}_{3}^{+}$ in correlation with $\mathrm{C}_{12} \mathrm{H}_{23} \mathrm{O}^{+}$is the peroxyhemiacetal corresponding to the carbonyl hydroperoxide (possible fragmentation at site 2 of peroxyhemiacetal, see inset in Fig. 2). Although the fragmentation of a peroxyhemiacetal standard in the HR-ToF-AMS can not be confirmed, the chemical mechanism prediction of aldehyde formation in the gas-phase and evidence for hydroperoxides in the gas- and particle-phase 
Table 3. HR-ToF-AMS ions with highest Pearson's $r$ values for $f_{\text {peak }}=0.2$ solution.

\begin{tabular}{|c|c|c|c|c|c|c|c|c|}
\hline $\begin{array}{l}\text { Pearson's r with } \\
\text { factor } 1\end{array}$ & Ion Formula & $\begin{array}{l}\text { Ion Mass } \\
\left(\mu \mathrm{g} \mathrm{m}^{-3}\right)\end{array}$ & $\begin{array}{l}\text { Pearson's r with } \\
\text { factor } 2\end{array}$ & Ion Formula & $\begin{array}{l}\text { Ion Mass } \\
\left(\mu \mathrm{g} \mathrm{m}^{-3}\right)\end{array}$ & $\begin{array}{l}\text { Pearson's r with } \\
\text { factor } 3\end{array}$ & Ion Formula & $\begin{array}{l}\text { Ion Mass } \\
\left(\mu \mathrm{g} \mathrm{m}^{-3}\right)\end{array}$ \\
\hline 0.888964 & $\mathrm{C}_{12} \mathrm{H}_{23} \mathrm{O}$ & 183.175 & 0.992157 & $\mathrm{C}_{12} \mathrm{H}_{23} \mathrm{O}_{2}$ & 199.17 & 0.978408 & $\mathrm{C}_{10} \mathrm{H}_{15} \mathrm{O}_{3}$ & 183.102 \\
\hline 0.858995 & $\mathrm{C}_{12} \mathrm{H}_{23} \mathrm{O}_{3}$ & 215.165 & 0.975248 & $\mathrm{C}_{8} \mathrm{H}_{13}$ & 109.102 & 0.970308 & $\mathrm{C}_{4} \mathrm{H}_{5} \mathrm{O}_{3}$ & 101.024 \\
\hline 0.854958 & $\mathrm{C}_{3} \mathrm{H}_{7} \mathrm{O}_{2}$ & 75.0446 & 0.973654 & $\mathrm{C}_{7} \mathrm{H}_{13} \mathrm{O}$ & 113.097 & 0.95434 & $\mathrm{C}_{8} \mathrm{H}_{11} \mathrm{O}_{3}$ & 155.071 \\
\hline 0.851494 & $\mathrm{C}_{6} \mathrm{H}_{12}$ & 84.0939 & 0.973188 & $\mathrm{C}_{7} \mathrm{H}_{13}$ & 97.1017 & 0.953511 & $\mathrm{C}_{5} \mathrm{H}_{7} \mathrm{O}_{3}$ & 115.039 \\
\hline 0.835077 & $\mathrm{C}_{5} \mathrm{H}_{11} \mathrm{O}_{2}$ & 103.076 & 0.972338 & $\mathrm{C}_{8} \mathrm{H}_{15} \mathrm{O}$ & 127.112 & 0.949821 & $\mathrm{C}_{9} \mathrm{H}_{13} \mathrm{O}_{3}$ & 169.087 \\
\hline 0.830188 & $\mathrm{C}_{4} \mathrm{H}_{9} \mathrm{O}_{2}$ & 89.0603 & 0.972216 & $\mathrm{C}_{7} \mathrm{H}_{11}$ & 95.0861 & 0.947504 & $\mathrm{C}_{7} \mathrm{H}_{11} \mathrm{O}_{3}$ & 143.071 \\
\hline 0.83002 & $\mathrm{C}_{5} \mathrm{H}_{10}$ & 70.0782 & 0.970214 & $\mathrm{C}_{12} \mathrm{H}_{21} \mathrm{O}_{2}$ & 197.154 & 0.94481 & $\mathrm{C}_{12} \mathrm{H}_{19} \mathrm{O}_{3}$ & 211.133 \\
\hline 0.819021 & $\mathrm{C}_{7} \mathrm{H}_{14}$ & 98.1096 & 0.969585 & $\mathrm{C}_{9} \mathrm{H}_{15}$ & 123.117 & 0.943721 & $\mathrm{C}_{10} \mathrm{H}_{16} \mathrm{O}_{3}$ & 184.11 \\
\hline 0.812879 & $\mathrm{C}_{2} \mathrm{H}_{5} \mathrm{O}_{2}$ & 61.0289 & 0.969189 & $\mathrm{C}_{6} \mathrm{H}_{11}$ & 83.0861 & 0.941672 & $\mathrm{C}_{10} \mathrm{H}_{13} \mathrm{O}_{3}$ & 181.087 \\
\hline 0.775934 & $\mathrm{C}_{4} \mathrm{H}_{8}$ & 56.0626 & 0.968232 & $\mathrm{C}_{6} \mathrm{H}_{11} \mathrm{O}$ & 99.081 & 0.939138 & $\mathrm{C}_{3} \mathrm{H}_{3} \mathrm{O}_{3}$ & 87.0082 \\
\hline
\end{tabular}

suggest that peroxyhemiacetal formation or other oligomerization processes are possible.

Figure 8 shows the PMF factor time series with the top 3 correlating HR-ToF-AMS ions. The $\mathrm{C}_{3} \mathrm{H}_{7} \mathrm{O}_{2}^{+}$ion at $\mathrm{m} / \mathrm{z} 75$, which is a suggested hydroperoxide tracer (Table 4), nearly overlaps factor 1 for the first $15 \mathrm{~h}$, after which the time trend of $\mathrm{C}_{3} \mathrm{H}_{7} \mathrm{O}_{2}{ }^{+}$decays more slowly than factor 1 ; this is because the hydroperoxide functionalization could also have a contribution to factor 2 , or later generations of oxidation products. $\mathrm{C}_{12} \mathrm{H}_{23} \mathrm{O}^{+}$at $m / z 183$ and $\mathrm{C}_{12} \mathrm{H}_{23} \mathrm{O}_{3}^{+}$at $m / z 215$ also have a high correlation, although these ions grow in slightly after the hydroperoxide ion at $m / z$ 75. The difference between the individual ions trends and the PMF time trace is expected since the PMF factor represents the bulk variation of the aerosol composition over time and is not necessarily expected to exactly overlap with individual ion trends. Additionally, due to the fragmentation in the HR-ToF-AMS, single ions can contribute to multiple factors. The top 10 ions with the highest Pearson's r values for each factor show this effect (Fig. A1). The chemical interpretation of factor 1 is also supported by comparison to the CIMS gas-phase measurement of positive mode $m / z$ 204, the suggested product being the carbonyl hydroperoxide (Fig. 10, Yee et al., 2012) as well as the MOVI-HRToF-CIMS heating-mode measurement of the $\mathrm{C}_{12} \mathrm{H}_{21} \mathrm{O}_{3}{ }^{+}$ion, which is likely the chemical ionization product of $\mathrm{C}_{12}$ dihydroperoxide (Fig. 11).

HR-ToF-AMS, CIMS, and MOVI-HRToF-CIMS measurements suggest that factor 2 represents the gas-phase partitioning of tri-functionalized products and their corresponding peroxyhemiacetals (see pink shaded boxes in Fig. 2). Factor 2 correlates highly with HR-ToF-AMS ion $\mathrm{C}_{12} \mathrm{H}_{23} \mathrm{O}_{2}^{+}$ at $m / z 199$, which is the suggested ion tracer for the hydroxy carbonyl hydroperoxide (OHCARBROOH). Factor 2 also correlates well with the CIMS gas-phase positive mode $m / z 219$, which is the suggested dicarbonyl hydroperoxide product (Fig. 10) and the MOVI-HRToF-CIMS heatingmode ion $\mathrm{C}_{9} \mathrm{H}_{15} \mathrm{O}_{4}^{+}$(Fig. 11). The MOVI-HRToF-CIMS ion has higher oxygen content than ions trending with factor 1 , which could suggest an additional functional group from further oxidation.

Factor 3 is likely the gas-particle partitioning of multifunctional (4 or more functional groups) products, as indicated by $\mathrm{HR}$-ToF-AMS ion $\mathrm{C}_{10} \mathrm{H}_{15} \mathrm{O}_{3}^{+}$at $\mathrm{m} / z 183$ and $\mathrm{C}_{12} \mathrm{H}_{19} \mathrm{O}_{3}^{+}$at $m / z 211$ (Fig. 7), which could be the tricarbonyl hydroperoxide product (TRICARBROOH). MOVIHRToF-CIMS data also support the addition of a highly oxidized product to the aerosol with the ion $\mathrm{C}_{10} \mathrm{H}_{15} \mathrm{O}_{3}^{+}$ trend (Fig. 11). Although the CIMS did not measure in the high $m / z$ range necessary for identifying greater than trifunctionalized gas-phase products, the CIMS gas-phase $\mathrm{C}_{8}$ carboxylic acid trace shows continual increase. This is consistent with factor 3 growth, the potential for acid formation in the chemical mechanism, and HR-ToF-AMS $\mathrm{CO}_{2}^{+}$ ion, which could be from either acid formation or multifunctional products (Fig. 10). These results support factor 3 containing highly functionalized compounds, and acidic compounds, either from gas-to-particle partitioning of highly oxidized products or possibly from condensed chemical conversion from products in factors 1 and 2 .

Factors 1 and 2 both exhibit a maximum with respect to time. A decrease after the maximum owing to wall deposition alone, addressed in Sect. 3.6, does not fully explain the decrease of these factors. The extent of evaporation of aerosol products is difficult to interpret from the gas-phase data. Other processes, such as cyclization or peroxyhemiacetal oligomerization, are possible (Tobias and Ziemann, 2000; Ziemann, 2003) but cannot be established unequivocally from HR-ToF-AMS data, as the fragments resulting from oligomerization are not unique. Masses greater than $m / z 300$ are observed in the MOVI-HRToF-CIMS spectra, which although difficult to assign exact elemental formulas, may suggest that products greater than $C_{12}$ exist in the aerosol. Chemical conversion likely contributes to the decrease in factors 1 and 2 and increase in factor 3 (although gas-phase partitioning of highly oxidized compounds could also be contributing to the increase in factor 3 ). The percentages of mass greater than $\mathrm{m} / \mathrm{z} 100$ for factors 2 and 3 are 


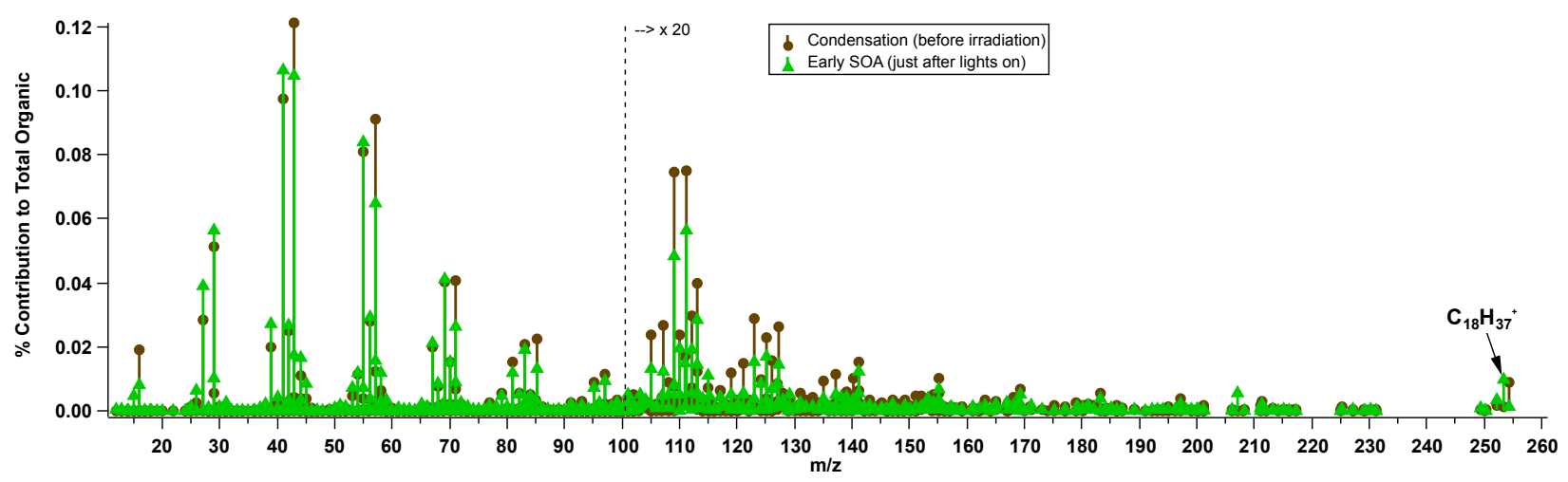

Fig. 9. Mass spectrum of octadecane condensing onto the seed before irradiation, and the relative mass spectrum just after lights on. The hypothesized octadecane-equivalent hydroperoxide fragment is marked at $m / z 253$.
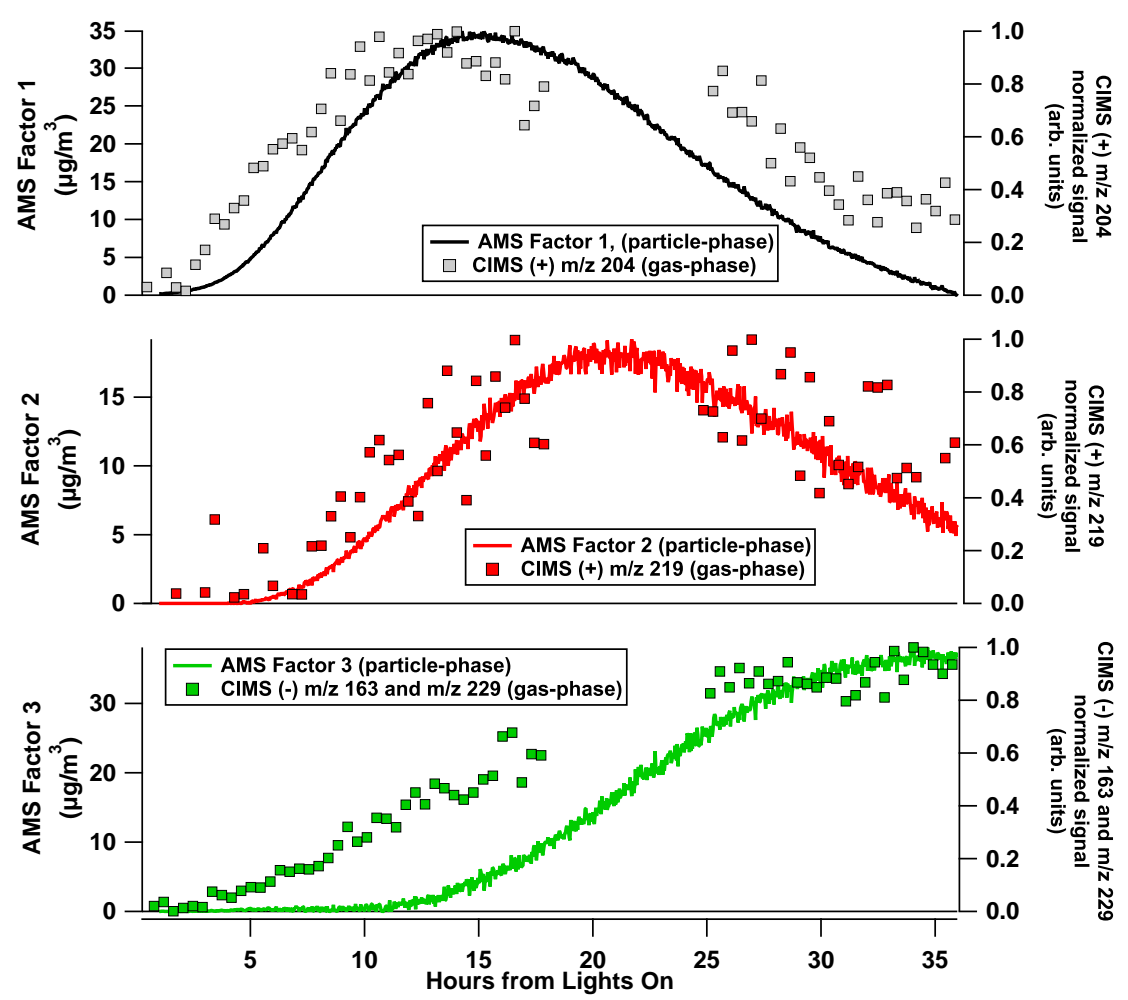

Fig. 10. Particle-phase HR-ToF-AMS factor time series with gas-phase CIMS time traces.

$8 \%$ and $5 \%$, respectively. The decrease of mass concentration of ions correlating with factor 2 may be a result of fragmentation in the aerosol. Molecular level identification of individual species from further MOVI-HRToF-CIMS analysis would be necessary to confirm this.

Other HR-ToF-AMS ions with $32 \mathrm{~m} / z$ difference that support a $\mathrm{C}_{12}$ functionalized hydroperoxide reacting with an aldehyde to form peroxyhemiacetal are listed in Table 2 . Other $32 \mathrm{~m} / \mathrm{z}$ pairs with fewer than 12 carbons exist, and may come from hydroperoxide formation in Channel 1 of the mechanism containing fragmentation of carbon chains fewer than 12 .

The proposed peroxyhemiacetal tracer ions behave differently under reduced HR-ToF-AMS temperature. In experiment 5 in Table 1 , the HR-ToF-AMS $600^{\circ} \mathrm{C}$ heater was turned off and only ionization (no vaporization) was used to sample the aerosol. During the time when the heater was turned off, the bulk of the organic ions decreased, since the ionization of the aerosol is contingent upon its vaporization. However, signal generated by the ions for the hypothesized 


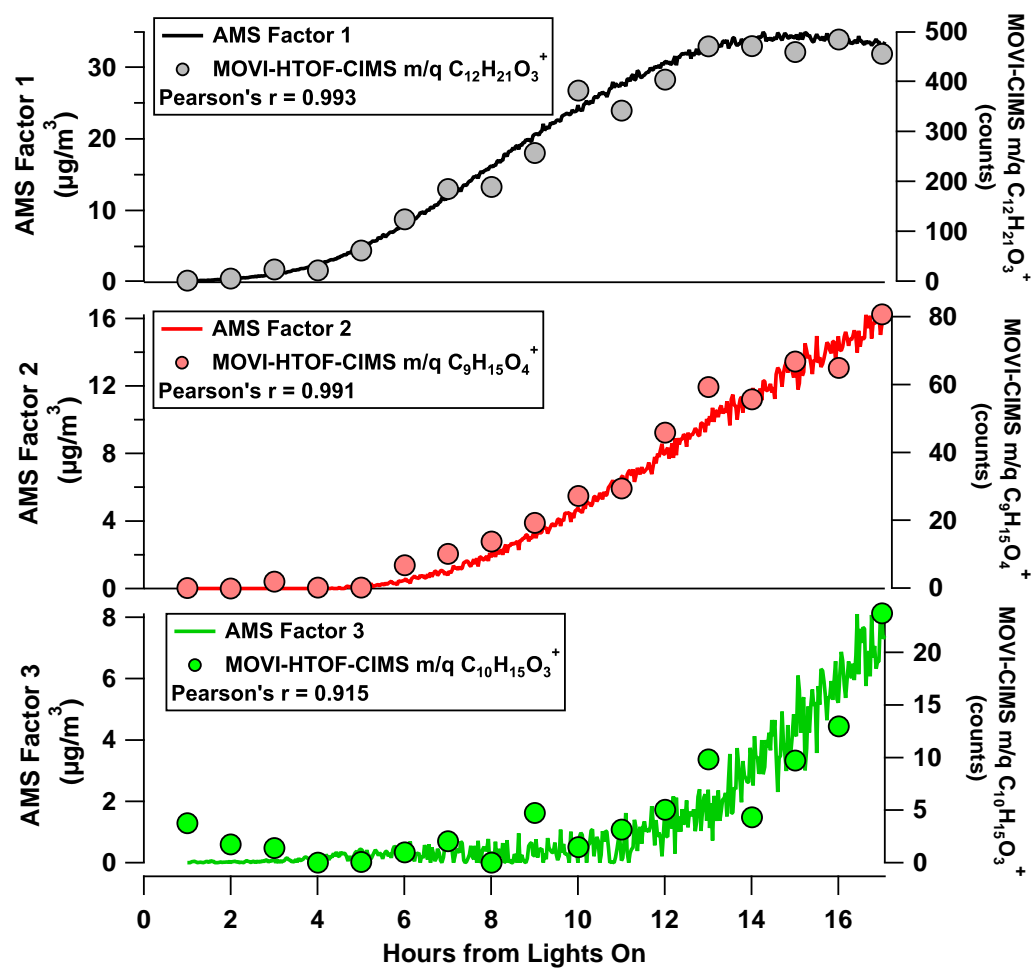

Fig. 11. Factor time series with MOVI-HRToF-CIMS heating-mode, aerosol-phase traces. Only the first $18 \mathrm{~h}$ of data is available for the MOVI-HRToF-CIMS data.

peroxyhemiacetal actually increased (Fig. 12). Since peroxyhemiacetals are unstable at high temperature, the decrease in temperature would stabilize peroxyhemiacetal, allowing the molecules to be more available for ionization.

It is important to note that the latter half of experiment 2 provides useful information in interpreting the chemistry of the aerosol. In the first $17 \mathrm{~h}$, all of the factors show only an increase (see Figs. 11 and A1). The time trends of factors 2 and 3 look very similar in the first $17 \mathrm{~h}$, but distinction becomes possible in the latter half of the experiment in which factor 2 decreases and factor 3 increases (Fig. 6). This explains perhaps why in a shorter experiment, two factors explain the data better (see Appendix A for further explanation on the effect of PMF on different lengths of experiment).

\subsection{Chamber processes}

Deposition of aerosol to the chamber walls decreases the suspended aerosol mass. PTOF-mode data are not available for the $34 \mathrm{~h}$ experiment discussed above. Experiment 4 was carried out, with a similar initial dodecane concentration, to explore the contribution from wall loss to the decrease in mass of the PMF factor time series. As expected, the average diameter of the aerosol mass distribution grew with increasing $\mathrm{OH}$ exposure (Fig. 13 and panel a1, a2 and a3 in Fig. 14). Since the wall loss rate is a function of diameter (Fig. 13, Loza et al., 2012), the size of the aerosol and composition at that size are important for factor dependent wall-loss corrections. Panel b of Fig. 14 shows the PMF factors (only 2 for a shorter experiment, see Sect. A2) as a function of time. "Time 1" is early in the experiment when the mass distribution is expected to have a major contribution from factor 1 . "Time 2" is at maximum growth in time of factor 1 and a large contribution from factor 2, and "Time 3" is when factor 2 has passed factor 1 in overall mass. The PMF results for the mass distributions (diameter is the independent variable now instead of time) are shown with the overall organic mass distribution to emphasize the contribution from factors 1 and 2 to each size bin (panel a1, a2, and a3 with b on Fig. 14). Since factor 1 is the first to condense onto the aerosol, some of its mass is lost more rapidly than factor 2 , which condenses later onto larger particles (which are lost by deposition at a slower rate). The mass fractions of factors 1 and 2 were calculated for each size bin for 12 mass distributions; this information was used to adapt the wall deposition calculations carried out by Loza et al. (2012) for individual factor wall loss corrections.

Even with wall loss correction, factor 1 shows a decrease, while factor 2 shows an increase; the cumulative mass loss by wall deposition for factor 1 at the end of the experiment is $18 \mu \mathrm{g} \mathrm{m}^{-3}$, which accounts for approximately $50 \%$ of the decrease in mass from the peak of factor 1 (panel c from Fig. 14). These results further support the hypothesis that the mass in the aerosol is undergoing chemical conversion. It is 


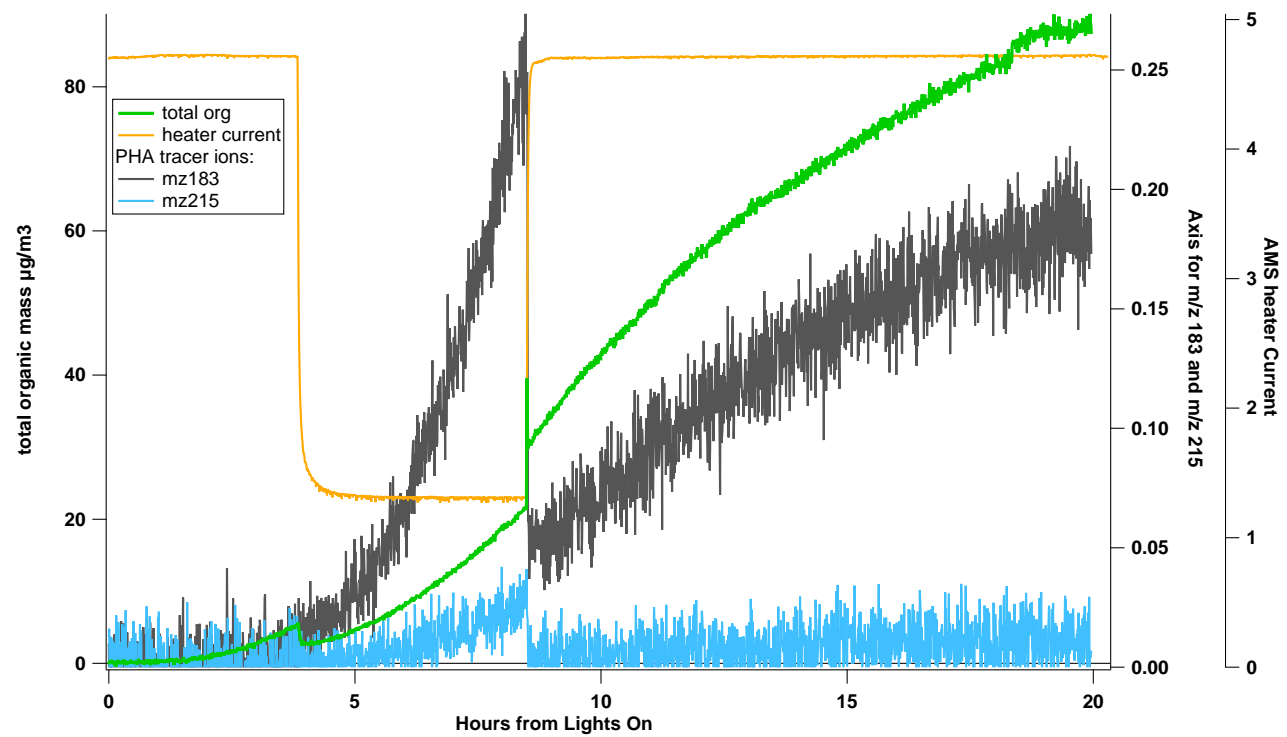

Fig. 12. Tracer ions for the carbonyl hydroperoxide increase while the bulk organic trace decreases when the $600^{\circ} \mathrm{C} \mathrm{HR}-\mathrm{ToF}-\mathrm{AMS}$ heater is turned off.

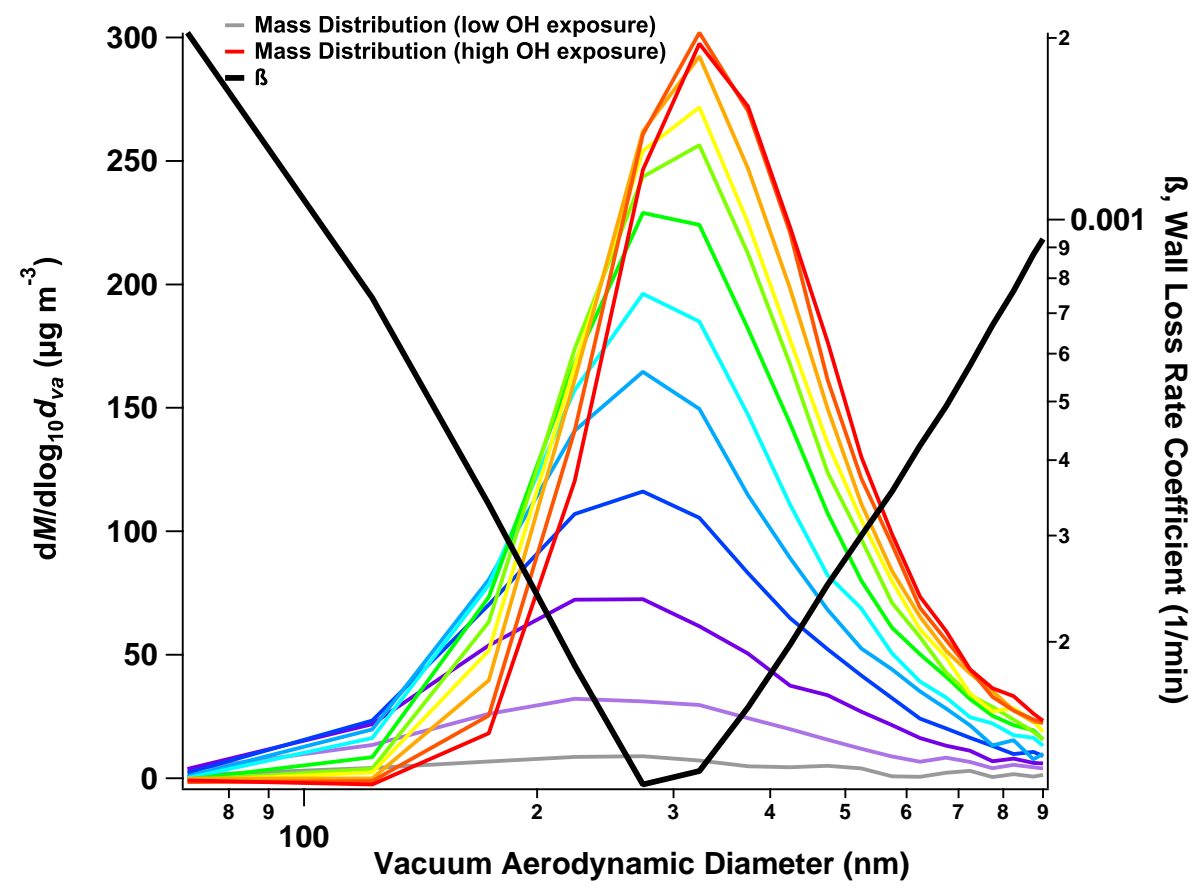

Fig. 13. The aerosol mass distribution grows from smaller diameter sizes to larger diameter sizes with increasing OH exposure (purple is low $\mathrm{OH}$ exposure, red is high $\mathrm{OH}$ exposure). The wall deposition rate coefficient is overlaid for comparison.

also important to note that the effects of wall loss on factors 1 and 2 differ as a result of the size distribution of the aerosol when the factor emerges.

\subsection{Van Krevelen diagram}

The Van Krevelen diagram has been used to represent the evolution of HR-ToF-AMS elemental ratios, $\mathrm{H}: \mathrm{C}$ vs. O : C, for both ambient and chamber-generated organic aerosols (Heald et al., 2010; Ng et al., 2011; Chhabra et al., 2011; Lambe et al., 2011, 2012). A slope of 0 on the diagram is 

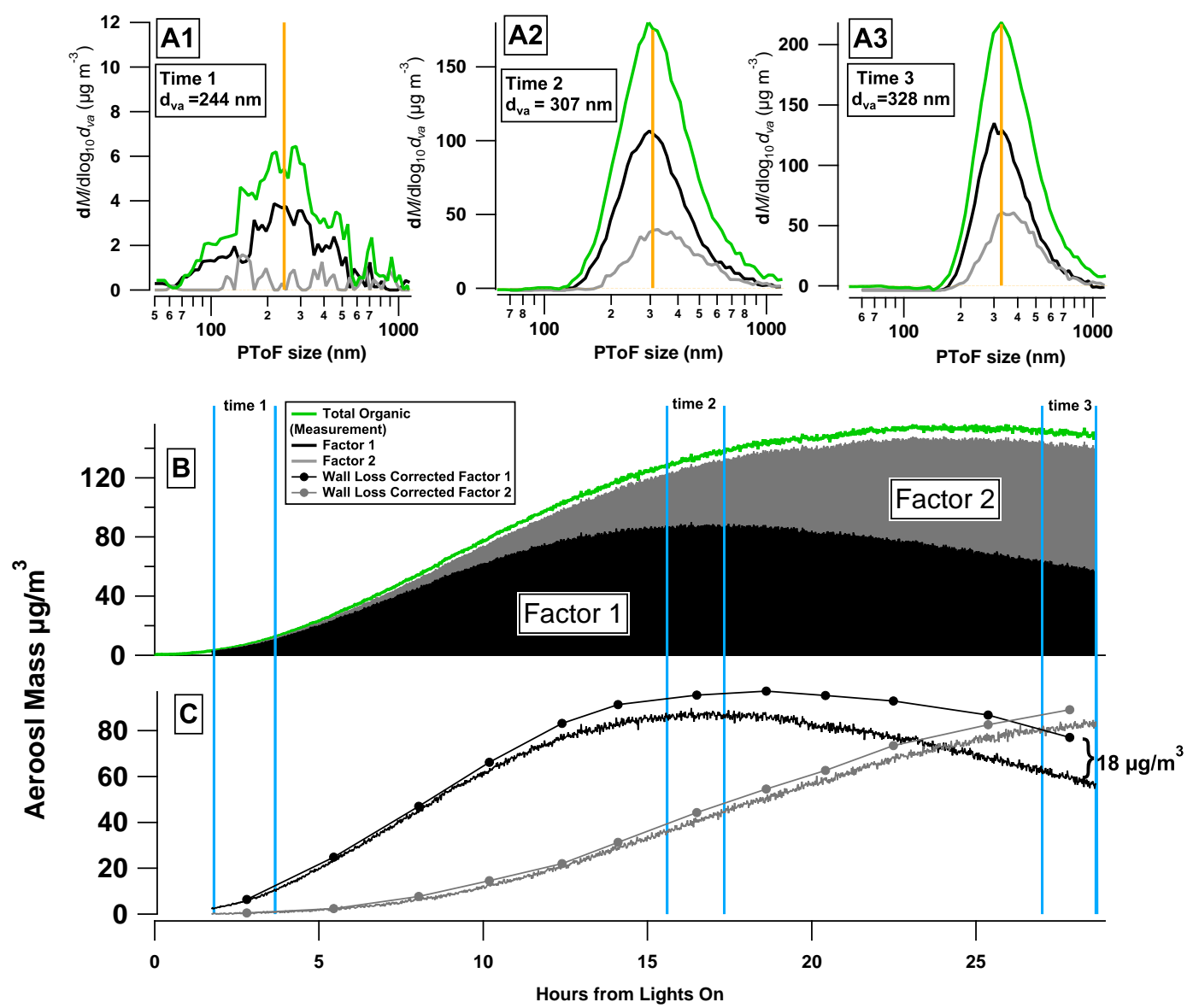

Fig. 14. Mass distributions (A1, A2 and A3) and time series (B) of total organic mass (green) broken down into 2 factors (black and grey). The average diameter for each mass distribution is highlighted by the yellow bar, and the time associated with each distribution is outlined with the two blue bars on the time series graphs. The wall-loss corrected versions of the individual factor time series are also shown (C).

consistent with peroxide or alcohol functionalization without carbon chain fragmentation. A slope of -1 is consistent with carboxylic acid or ketone/aldehyde and alcohol addition on the same carbon chain, and a slope of -2 is consistent with ketone/aldehyde addition (Van Krevelen, 1950; Heald et al., 2010). Lambe et al. (2012) report the slopes for low- $\mathrm{NO}_{\mathrm{x}}$ photooxidation of long chain alkanes $\left(\mathrm{C}_{10}, \mathrm{C}_{15}\right.$, and $\left.\mathrm{C}_{17}\right)$ in a PAM reactor in two regimes in terms of the $\mathrm{O}: \mathrm{C}$ ratio. For $\mathrm{O}: \mathrm{C}<0.3$, the slope is relatively steep $(-1.3 \pm 0.2)$, while for $\mathrm{O}: \mathrm{C}>0.3$ the slope becomes less negative $(-0.7 \pm 0.1)$. Lambe et al. (2012) attribute this change in slope to a transition from functionalization to fragmentation dominated reactions. The dodecane aerosol composition data presented here lie primarily in the regime where $\mathrm{O}: \mathrm{C}<0.3$, with a slope of -1.16 that is consistent with Lambe et al. (2012) in this $\mathrm{O}: \mathrm{C}$ range.

As discussed by Ng et al. (2011) and Lambe et al. (2012), the slope on a Van Krevelen diagram can represent a combination of several functionalities and generally requires molecular level information for further interpretation. The
PMF analysis links the HR-ToF-AMS aerosol spectrum to molecular level detail when compared to measurements from CIMS and MOVI-HRToF-CIMS. Concurrent with our chemical understanding, over $34 \mathrm{~h}$ of oxidation, the dodecane low$\mathrm{NO}_{\mathrm{x}}$ system is characterized by the addition of peroxides and ketone/aldehyde functionalization, as opposed to solely carboxylic acid formation. PMF factor 1 (black marker in Fig. 15) overlaps the bulk composition data (grey markers) near the initial growth at low $\mathrm{OH}$ exposure. Factor 2 (red marker in Fig. 15) has a similar $\mathrm{H}: \mathrm{C}$ ratio as factor 1, but higher $\mathrm{O}: \mathrm{C}$ ratio. The slope between factors 1 and 2 , $m_{12}=0.12$, is characteristic of either hydroxy or peroxide addition. We have already shown that factor 2 describes the gas-phase partitioning of hydroperoxide species (Sect. 3.5). The addition of hydroperoxide functional groups is not obvious from the bulk $\mathrm{H}: \mathrm{C}$ and $\mathrm{O}: \mathrm{C}$ ratios (slope $=-1.16$ ), but only from the PMF factor elemental ratios. The $\mathrm{H}: \mathrm{C}$ and $\mathrm{O}: \mathrm{C}$ ratios of factor 3 (green marker in Fig. 15) overlaps the data (grey markers) at the end of the experiment. The slope from factor 2 to $3, m_{23}=-1.78$, is characteristic of 


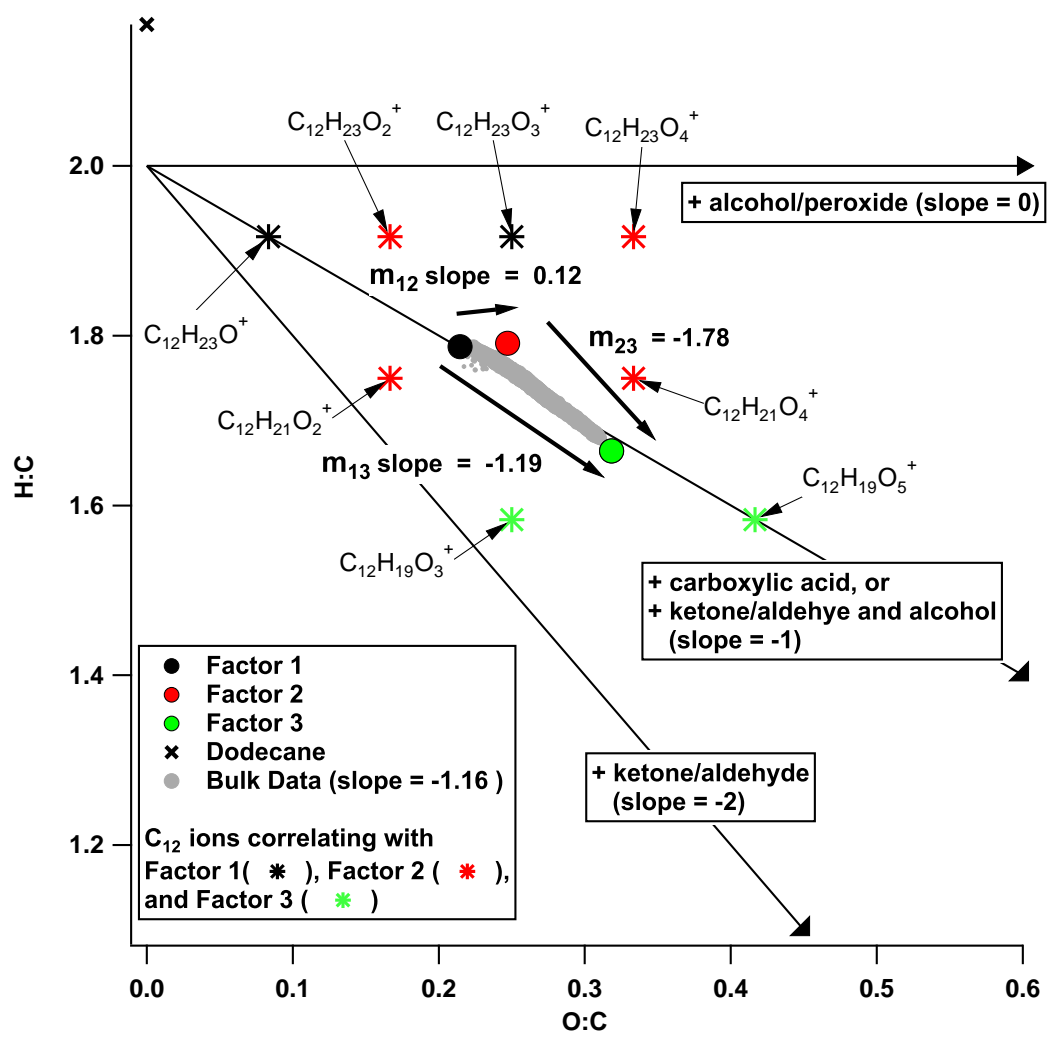

Fig. 15. Van Krevelen diagram for low- $\mathrm{NO}_{\mathrm{x}}$ photooxidation of dodecane. HR-ToF-AMS bulk composition data are indicated by the grey markers and PMF factors 1-3 are shown by the black, red, and green circle markers. $\mathrm{C}_{12}$ ions, which are the ions retaining the most molecular-level detail, with high correlation to each factor are also displayed by the black, red, and green star markers.

the addition of products with carbonyl or ketone functionalization. The slope between factor 1 and $3, m_{13}=-1.19$, is consistent with either carboxylic acid formation or ketone/aldehyde and alcohol addition to a product in factor 1 . The slopes between the factor elemental ratios help indicate the combinations of functionality in the aerosol, with more clarity than one slope from the bulk elemental analysis. The $\mathrm{C}_{12}$ ion fragments correlating the highest with each factor and hypothesized to be mono-, di-, or tri- functionalized $\mathrm{C}_{12}$ hydroperoxides and/or functionalized peroxyhemiacetals are also displayed on Fig. 15.

\section{Conclusions}

In the present work, PMF has been applied to high-resolution chamber HR-ToF-AMS mass spectra to deduce the chemical and physical processes associated with low- $\mathrm{NO}_{\mathrm{x}}$ dodecane SOA formation and aging. PMF untangles some of the complexity of SOA mass spectra by providing a mass spectral signature, with ion tracers, associated with a group of molecules at a distinct oxidation level. Factor 1 represents the gas-phase partitioning of initial oxidation products with two functional groups, factor 2 is the further oxidized, tri- functionalized products incorporating into the particle phase, and factor 3 is the partitioning of extended oxidation products quadruply functionalized. All three factors could also include oligomerization processes and contributions from wall-loss.

An octadecane low- $\mathrm{NO}_{\mathrm{x}}$ photooxidation experiment was conducted to develop a hydroperoxide standard for the HRToF-AMS, from which the alkyl-ion $\mathrm{C}_{18} \mathrm{H}_{37}^{+}$at $m / z 253$ and $\mathrm{C}_{3} \mathrm{H}_{7} \mathrm{O}_{2}^{+}$at $m / z \quad 75$ were identified as hydroperoxide ion tracers. With the PMF factor results, in combination with the SOA mechanism, CIMS, and MOVI-HRToF-CIMS measurements, the peroxyhemiacetal ion tracers were proposed, such as the $\mathrm{C}_{12} \mathrm{H}_{23} \mathrm{O}^{+}$at $m / z 183$ and $\mathrm{C}_{12} \mathrm{H}_{23} \mathrm{O}_{3}^{+}$at $m / z 215$ for the carbonyl hydroperoxide-peroxyhemiacetal.

The Van Krevelen diagram of the data, supported by the chemical interpretation of the dodecane low- $\mathrm{NO}_{\mathrm{x}}$ oxidation, is consistent with the addition of peroxides and ketone/aldehyde functionalization rather than solely carboxylic acids. While the bulk experimental elemental ratios exhibit a slope of -1.16 , the change in $\mathrm{H}: \mathrm{C}$ and $\mathrm{O}: \mathrm{C}$ ratios from factors 1 to 2 reveals a slope of 0.12 , strongly indicating hydroperoxide addition to the aerosol. The elemental ratios between factors 2 and 3 have a slope of -1.78 , indicating adding of aldehyde/carbonyl functionalization, and the slope between factor 1 and 3 is -1.19 , indicating either 
Table 4. Distinct ions present in early $\mathrm{C}_{18}$ SOA formation.

\begin{tabular}{|c|c|c|c|}
\hline $\begin{array}{l}\text { Ion } \\
\text { Formula }\end{array}$ & $\begin{array}{l}\text { Exact } \\
\text { Mass }\end{array}$ & $\begin{array}{c}\% \text { Difference from } \mathrm{C}_{18} \\
\text { Condensation MS }\end{array}$ & $\begin{array}{l}\text { Mass Fraction in } \\
\text { SOA Spectrum }\end{array}$ \\
\hline $\mathrm{C}_{3} \mathrm{H}_{7} \mathrm{O}_{2}$ & 75.0446 & 0.99 & 0.0005 \\
\hline $\mathrm{CO}$ & 27.9949 & 0.99 & 0.0007 \\
\hline $\mathrm{CO}_{2}$ & 43.9898 & 0.99 & 0.0007 \\
\hline $\mathrm{C}$ & 12.0000 & 0.99 & 0.0006 \\
\hline $\mathrm{C}_{2} \mathrm{H}_{2} \mathrm{O}$ & 42.0106 & 0.99 & 0.0017 \\
\hline $\mathrm{CHO}_{2}$ & 44.9977 & 0.99 & 0.0006 \\
\hline $\mathrm{CH}$ & 13.0078 & 0.99 & 0.0006 \\
\hline $\mathrm{CH}_{3}$ & 15.0235 & 0.99 & 0.0048 \\
\hline $\mathrm{C}_{5} \mathrm{H}_{3}$ & 63.0235 & 0.99 & 0.0006 \\
\hline $\mathrm{C}_{18} \mathrm{H}_{37}$ & 253.2900 & 0.98 & 0.0005 \\
\hline $\mathrm{C}_{5} \mathrm{H}_{7} \mathrm{O}$ & 83.0497 & 0.98 & 0.0024 \\
\hline $\mathrm{C}_{4} \mathrm{H}_{9} \mathrm{O}$ & 73.0653 & 0.98 & 0.0014 \\
\hline $\mathrm{C}_{2} \mathrm{H}_{3} \mathrm{O}$ & 43.0184 & 0.97 & 0.0174 \\
\hline $\mathrm{C}_{6} \mathrm{H}_{6}$ & 78.0470 & 0.96 & 0.0014 \\
\hline $\mathrm{CH}_{3} \mathrm{O}$ & 31.0184 & 0.95 & 0.0027 \\
\hline $\mathrm{C}_{2} \mathrm{H}_{2}$ & 26.0156 & 0.95 & 0.0066 \\
\hline $\mathrm{C}_{3} \mathrm{H}_{7} \mathrm{O}$ & 59.0497 & 0.95 & 0.0036 \\
\hline $\mathrm{C}_{2} \mathrm{H}_{5} \mathrm{O}$ & 45.0340 & 0.94 & 0.0084 \\
\hline $\mathrm{C}_{3} \mathrm{H}$ & 37.0078 & 0.94 & 0.0008 \\
\hline $\mathrm{C}_{4} \mathrm{H}_{2}$ & 50.0157 & 0.94 & 0.0009 \\
\hline $\mathrm{C}_{3} \mathrm{H}_{3} \mathrm{O}$ & 55.0184 & 0.94 & 0.0072 \\
\hline $\mathrm{CHO}$ & 29.0027 & 0.93 & 0.0103 \\
\hline $\mathrm{C}_{4} \mathrm{H}_{4}$ & 52.0313 & 0.93 & 0.0012 \\
\hline $\mathrm{C}_{2} \mathrm{H}_{5} \mathrm{O}_{2}$ & 61.0289 & 0.93 & 0.0007 \\
\hline $\mathrm{C}_{3} \mathrm{H}_{6} \mathrm{O}$ & 58.0419 & 0.93 & 0.0118 \\
\hline $\mathrm{C}_{3} \mathrm{H}_{4} \mathrm{O}$ & 56.0262 & 0.93 & 0.0010 \\
\hline $\mathrm{C}_{5} \mathrm{H}_{5} \mathrm{O}$ & 81.0340 & 0.92 & 0.0010 \\
\hline $\mathrm{C}_{4} \mathrm{H}_{5}$ & 53.0391 & 0.92 & 0.0074 \\
\hline $\mathrm{C}_{3} \mathrm{H}_{4}$ & 40.0313 & 0.92 & 0.0041 \\
\hline $\mathrm{C}_{5} \mathrm{H}_{10} \mathrm{O}$ & 86.0732 & 0.92 & 0.0005 \\
\hline $\mathrm{C}_{5} \mathrm{H}_{11} \mathrm{O}$ & 87.0810 & 0.92 & 0.0005 \\
\hline $\mathrm{C}_{9} \mathrm{H}_{7}$ & 115.0550 & 0.92 & 0.0006 \\
\hline $\mathrm{C}_{4} \mathrm{H}_{6} \mathrm{O}$ & 70.0419 & 0.92 & 0.0019 \\
\hline $\mathrm{C}_{2} \mathrm{H}_{4} \mathrm{O}$ & 44.0262 & 0.92 & 0.0167 \\
\hline $\mathrm{C}_{6} \mathrm{H}_{8}$ & 80.0626 & 0.92 & 0.0013 \\
\hline $\mathrm{C}_{3} \mathrm{H}_{2}$ & 38.0157 & 0.91 & 0.0020 \\
\hline $\mathrm{C}_{2} \mathrm{H}_{3}$ & 27.0235 & 0.91 & 0.0390 \\
\hline $\mathrm{C}_{5} \mathrm{H}_{5}$ & 65.0391 & 0.91 & 0.0020 \\
\hline $\mathrm{C}_{6} \mathrm{H}_{11} \mathrm{O}$ & 99.0810 & 0.91 & 0.0015 \\
\hline $\mathrm{C}_{4} \mathrm{H}_{7} \mathrm{O}$ & 71.0497 & 0.91 & 0.0089 \\
\hline $\mathrm{C}_{3} \mathrm{H}_{3}$ & 39.0235 & 0.91 & 0.0271 \\
\hline $\mathrm{C}_{4} \mathrm{H}_{3}$ & 51.0235 & 0.91 & 0.0016 \\
\hline $\mathrm{C}_{3} \mathrm{H}_{5} \mathrm{O}$ & 57.0340 & 0.90 & 0.0158 \\
\hline
\end{tabular}

* Early Oxidation MS-Condensation MS)/Condensation MS

carboxylic acid formation or aldehyde/ketone and alcohol addition. With the aid of the PMF results, the experimental data displayed on the Van Krevelen diagram can be broken down into contributions from different types of functionality.

Size-dependent composition was utilized to determine the extent of wall-loss deposition affecting factors 1 and 2 . The wall deposition contributed differently to each factor, but does not entirely explain the factor mass decrease; the decrease unexplained by wall loss deposition is attributed to chemical aging of the aerosol.
The chamber photooxidation HR-ToF-AMS PMF results facilitate the interpretation of SOA chemical and physical processes by linking the bulk AMS aerosol composition data to molecular level information provided by CIMS and MOVI-HRToF-CIMS measurements.

\section{Appendix A}

SOA formation from a single source in a laboratory is characterized by smooth aerosol growth (Fig. A1); the wellbehaved nature of ion signals and their associated errors is ideal for application of PMF. The size of the organic signal input matrix for PMF of experiment 2 in Table 1 is $1050 \times 325$. The columns of the matrix correspond to individual identified ions. High resolution stick intensities for identified ions at fractional $m / z$ 's from $12-300$ were used. AMS ion identification in the $m / z$ 101-300 range was aided by the dodecane low- $\mathrm{NO}_{\mathrm{x}}$ chemical mechanism, CIMS gas-phase measurements, and MOVI-CIMS aerosol measurements. Not all of the individual ions identified were included in PMF analysis, due to $S / N$ constraints.

The ions included in PMF analysis and the solution justification are discussed here. The organic matrix was calculated using PIKA's "Open" minus "Closed" option for highresolution ions with an average signal-to-noise ratio $(S / N)$ greater than 0.2 . Signals with a $S / N$ between 0.2 and 2 were down-weighted by a factor of 3 , as recommended by Paatero and Hopke (2003). The error matrix was calculated in PIKA in the standard way using "Open" minus "Closed" errors. The errors $(\sigma)$ normalize the residuals $(e)$ for the minimization function routine of PMF, $Q$; therefore, good quantification of errors is needed. For an input matrix of $n \times m$, the PMF minimization function from Ulbrich et al. (2009), is:

$Q=\sum_{i=1}^{n} \sum_{j=1}^{m}\left(e_{i j} / \sigma_{i j}\right)^{2}$

Careful consideration was given when choosing the ions for PMF. Even though the ion may appear to be present in the ion fitting window in PIKA, sometimes the time trend of this ion is too noisy for PMF. Noisiness in the time trend can be introduced when there are: (a) ions that are in the shoulder of a larger ion at the same nominal mass (i.e., $\mathrm{C}_{3} \mathrm{H}_{3} \mathrm{O}_{5}^{+}$is in the shoulder of the much larger ion $\mathrm{C}_{8} \mathrm{H}_{7} \mathrm{O}^{+}$at $m / z$ 119), (b) ions that are in the valley of two larger ions at the same nominal mass (i.e., the $\mathrm{C}_{3} \mathrm{H}_{7}^{+}$ion is in-between $\mathrm{C}_{3} \mathrm{H}_{3} \mathrm{O}_{3}^{+}$and $\mathrm{C}_{4} \mathrm{H}_{7} \mathrm{O}_{2}^{+}$at $m / z$ 87), (c) ions that exhibit a strong signal in the closed spectra, but only a small signal in the difference spectra (i.e., $\mathrm{C}_{10} \mathrm{H}_{7}^{+}$at $m / z$ 127), and/or (d) an ion is coincident with another ion that is expected to be there (i.e., the isotope of $\mathrm{N}_{2}^{+}$ion and $\mathrm{CHO}^{+}$ion are extremely close in exact mass). If ions like the ones mentioned above are included in PMF, then there is considerable noise in the time trend 


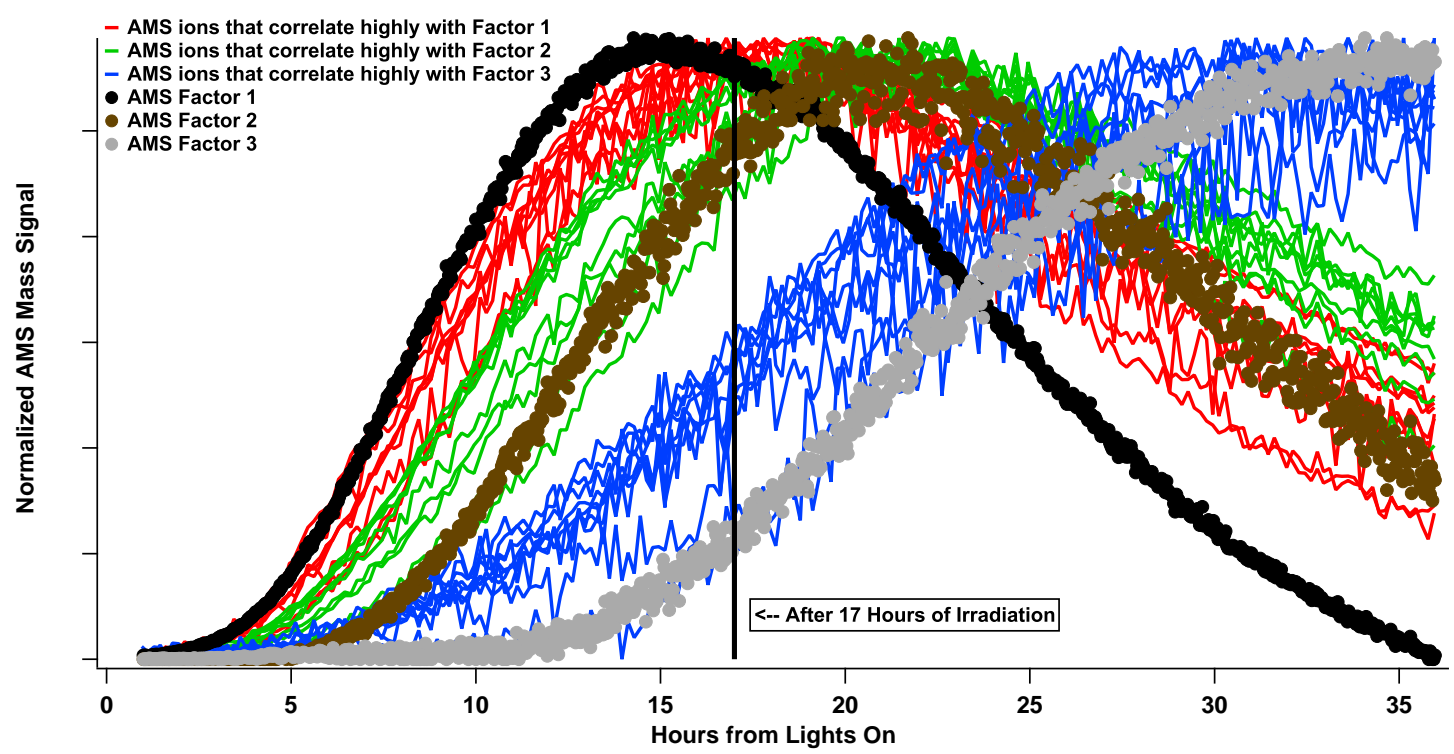

Fig. A1. Normalized mass signals from the AMS PMF factor time series are plotted with the AMS ions that have the highest correlations with those factors (ions listed in Table 3).

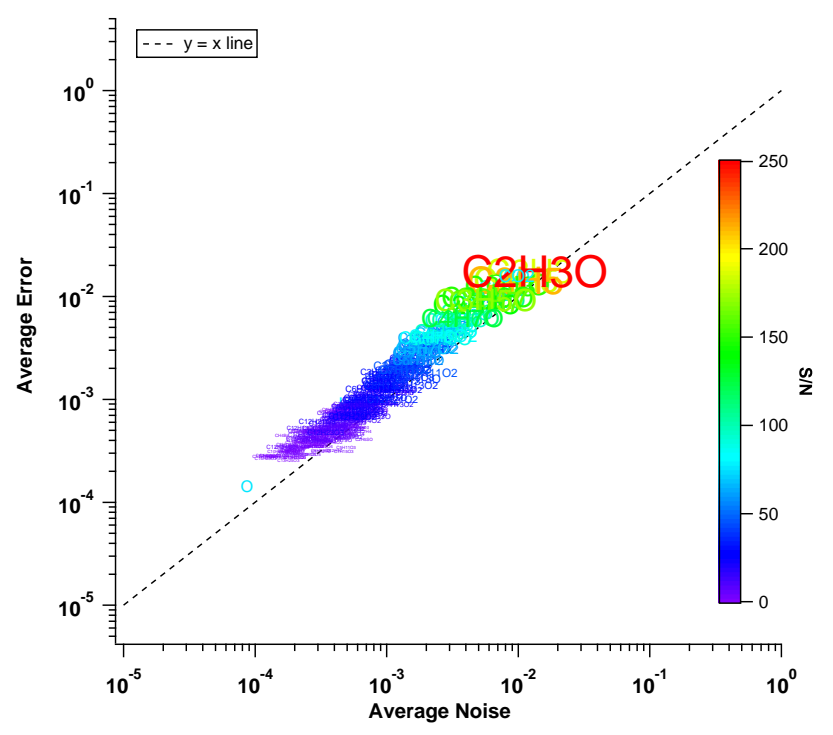

Fig. A2. Average error vs. the average noise for each ion is plotted along with the $\mathrm{y}=\mathrm{x}$ line. The marker is labeled by the ion it represents and is colored and sized by the $S / N$ ratio of that ion. If the marker lies directly on the $\mathrm{y}=\mathrm{x}$ line, this means the calculated errors have captured the noise in the ion signal, which is critical for PMF analysis.

of $Q / Q_{\text {expected. This noisiness results from peak fitting ions }}$ that experience large interference from other (often larger) ions, and should not be considered for PMF. An effective diagnostic to determine which ions to exclude from PMF is to calculate the $S / N$ of each ion using the errors generated in PIKA $\left(S / N_{\text {error }}\right)$, and then compare that to the $S / N$ using the

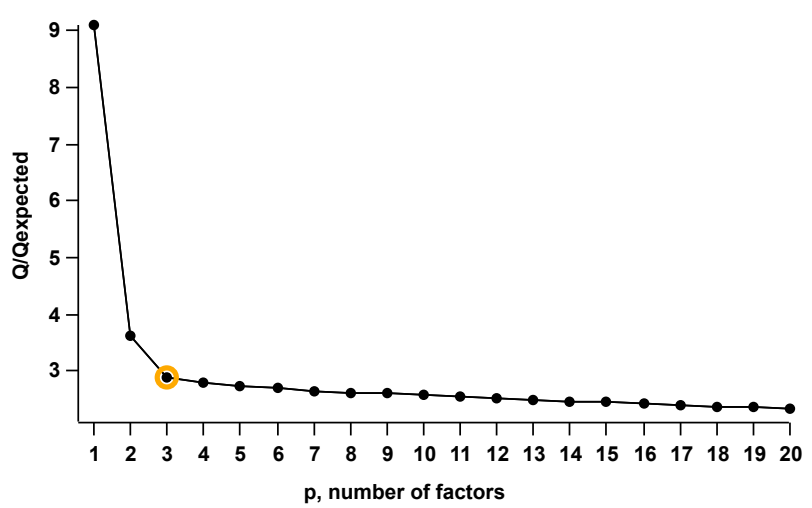

Fig. A3. $Q / Q_{\exp }$ vs. $p$, number of factors. The solution chosen is highlighted by the yellow circle.

observed noise ( $\left.S / N_{\text {noise }}\right)$. The observed noise is calculated by smoothing the data using the binomial smoothing function in Igor (order of smoothing is chosen by user) and then subtracting the data from the smoothed data at each time point. Since the equation for errors in PIKA does not consider noise introduced by ion fitting (in the a., b., c., and d. scenarios described above), the $S / N_{\text {noise }}$ is a good way to asses how well the ion is quantified. If $S / N_{\text {error }}$ is much different than the $S / N_{\text {noise }}$, then either the ion should not be fit because it is a minor ion, or it is an ion described by a., b., c., or d. above, and should be removed from PMF analysis. Figure A2 shows the time-averaged error vs. time-averaged noise for each ion. The marker is labeled by the ion it represents and is sized and colored by its $S / N$. A marker lying on the $\mathrm{y}=\mathrm{x}$ line means that the calculated errors in PIKA captured the noisiness of 

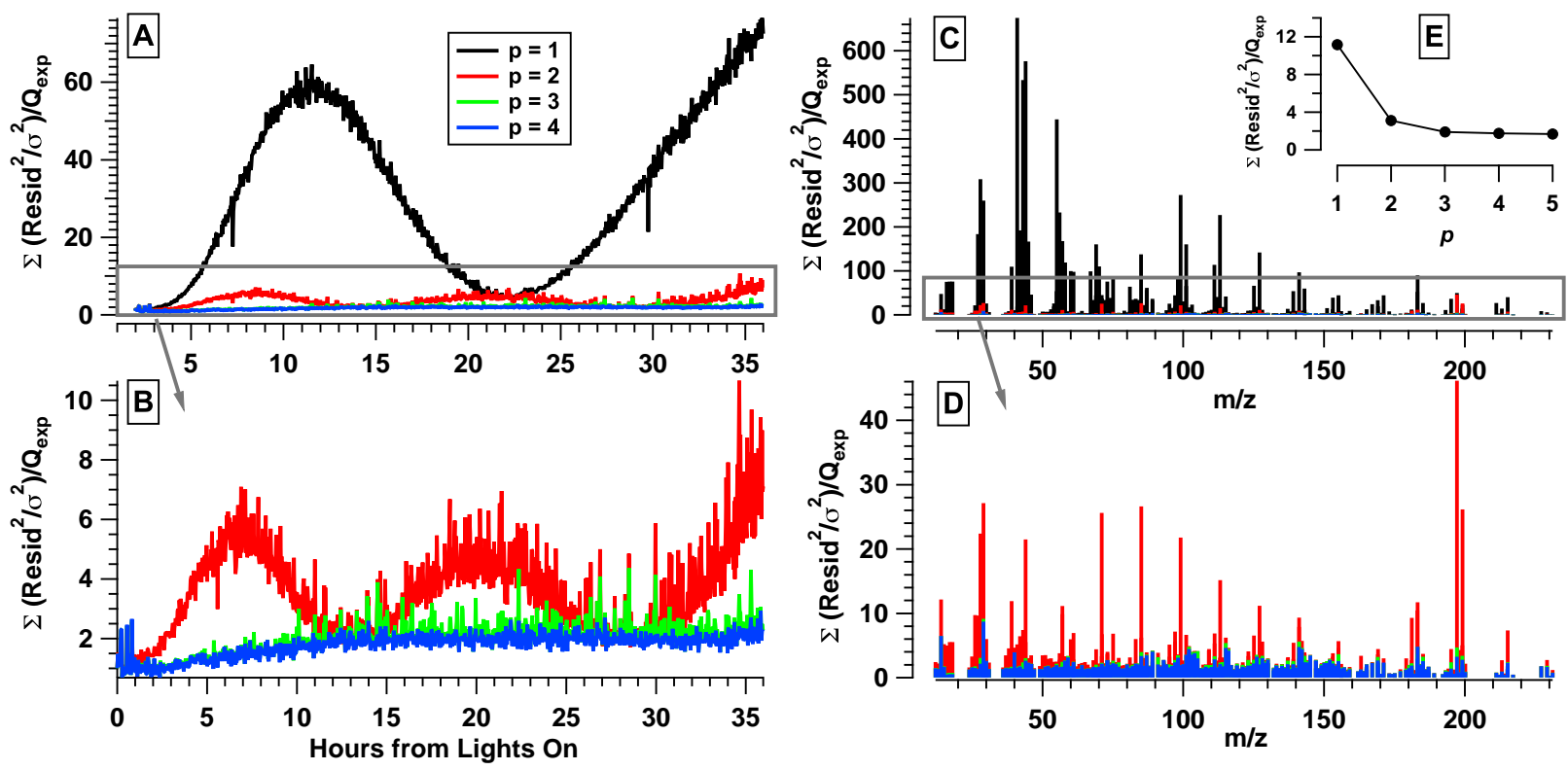

Fig. A4. The ratio of $Q / Q_{\text {expected }}$ for $p=1,2,3$, and 4 is used as a diagnostic in determining the number of factors in PMF analysis. Time series trend of $Q / Q_{\text {expected }}$ for $p=1$ through $p=4$ solutions (A) and (B) clearly show that at least three factors are needed to describe the solution. The difference between the $p=3$ and 4 solutions is minor, with the $p=4$ solution having the same trend as the $p=3$, but with less

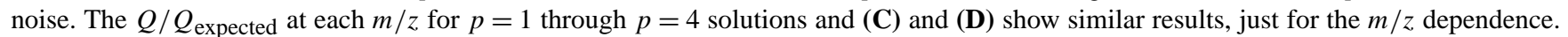
The overall time trend and $\mathrm{m} / \mathrm{z}$ contributions to the $Q / Q_{\text {expected }}$ at each factor are also presented (E).

the ion, which is essential for PMF analysis. The noisiness in the $Q / Q_{\text {expected }}$ time trend results from some noisy ions that were selected to remain in the input PMF analysis because the time trend of the ions, albeit noisy, appears to contain useful time trend information. This must be decided by the user for each system analyzed with PMF. No smoothed or averaged data were used for PMF, albeit averaging is recommended for future chamber PMF studies (Paatero, 2012).

The optimization function, $Q$, for PMF involves the minimization of the scaled residual at each mass over time (U1brich et al., 2009). Figure A3 shows the initial decrease in $Q / Q_{\text {expected }}$ with the addition of one factor from $p=1$ to $p=2$, which is expected for any data set with enough variability to run PMF. And then there is a slight decrease between $p=2$ and $p=3$. After $p=3$, the decrease in

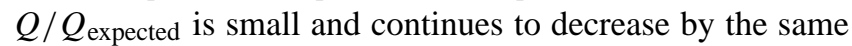
amount with each increase in $p$ and never flattens out. At $p=3$, the solution has reached a point at which no additional information is gained in adding another factor. It is useful to remember that in PMF, the factor mass spectral profiles are constant, and so one has to assume that the same is true for the actual SOA. The numerous processes associated with continuous oxidation of the gas and aerosol phase may invalidate this assumption, and so this may be why the $Q / Q_{\text {expected }}$ never flattens out. This behavior can make it difficult to select a solution. A good strategy is to examine how both specific ions and the majority of the ions are reconstructed by the fac- torization and if individual high $m / z$ ions (tracer ions) trend with each factor time series (see Fig. 8).

The time series of the sum of the residuals and the $Q / Q_{\text {expected }}$ is also useful in determining a solution. Any major structure in either of these parameters would suggest that additional factors are needed to describe the data. Figure A4 shows these two parameters for the $p=1, p=2, p=3$ and $p=4$ solution for the all ion iteration of PMF. There is clear structure in both the $p=1$ and $p=2$ solutions, whereas the $p=3$ and $p=4$ solutions have a flat sum of residuals and a relatively flat and small $Q / Q_{\text {expected }}$. There is little difference between the $p=3$ and $p=4$ solutions, so the addition of another factor would not enhance the information learned from the factorization from a residual point of view. The reason why the $Q / Q_{\text {expected }}$ has a slightly curved shape for both the $p=3$ and $p=4$ solutions arises from variability in the mass spectra that is beyond what is explained by the input noise. This may be a consequence of the composition of the aerosol becoming more complex, combined with the assumption of PMF that the factor must have a constant mass spectral profile (which does not hold with these systems).

Map plots were made for the $p=2$ and $p=3$ solutions (Figs. A5 and A6). In these plots, a red dot indicates the residual $_{i j}>\operatorname{error}_{i j}$, a blue dot is where residual $i_{i j}<-\operatorname{error}_{i j}$, and a white dot is where $-\operatorname{error}_{i j}<\operatorname{residual}_{i j}<\operatorname{error}_{i j}$. For a two factor solution (Fig. A5) there is clearly a non-random 


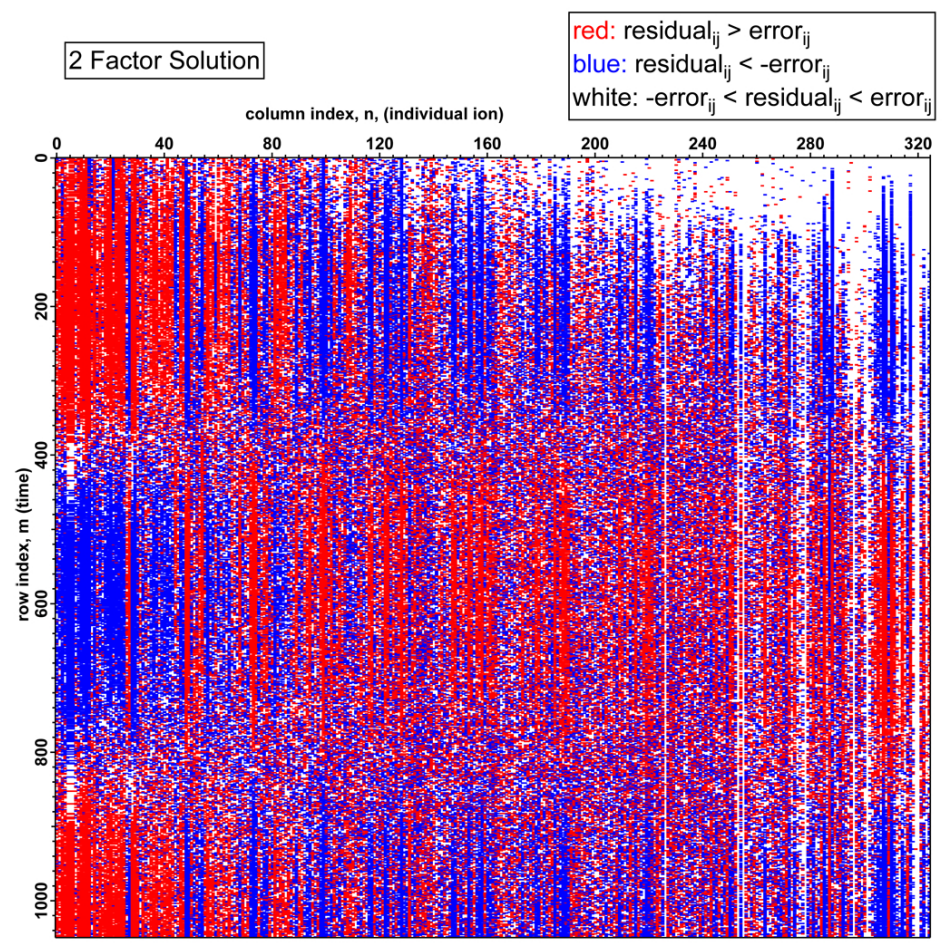

Fig. A5. The map plot for the two factor solution displays a red dot where the residual ${ }_{i j}>$ error $_{i j}$, a blue dot where residual ${ }_{i j}<-$ error $_{i j}$, and a white dot where $-\operatorname{error}_{i j}<\operatorname{residual}_{i j}<\operatorname{error}_{i j}$. For a two-factor solution there is clearly a non-random pattern, indicating two factors do not adequately describe the data.

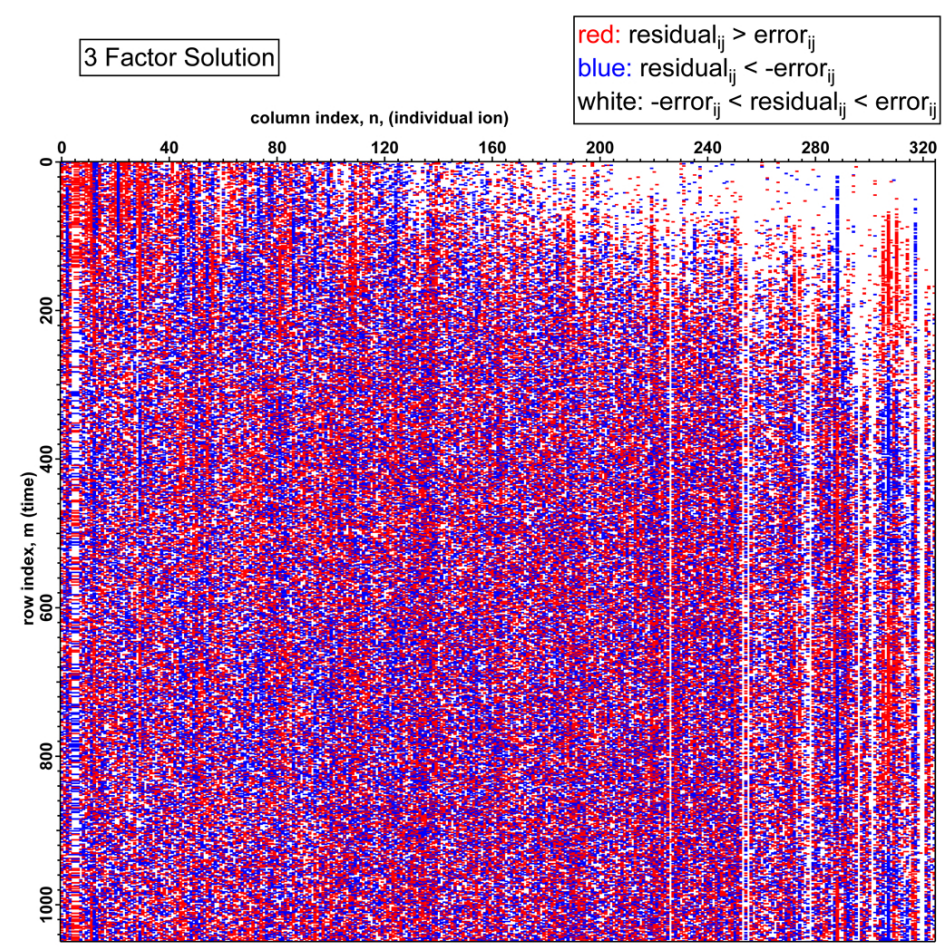

Fig. A6. The map plot, as described in Fig. A5 is shown for 3 factors. The pattern is random, indicating 3 factors describe the data variation well. 

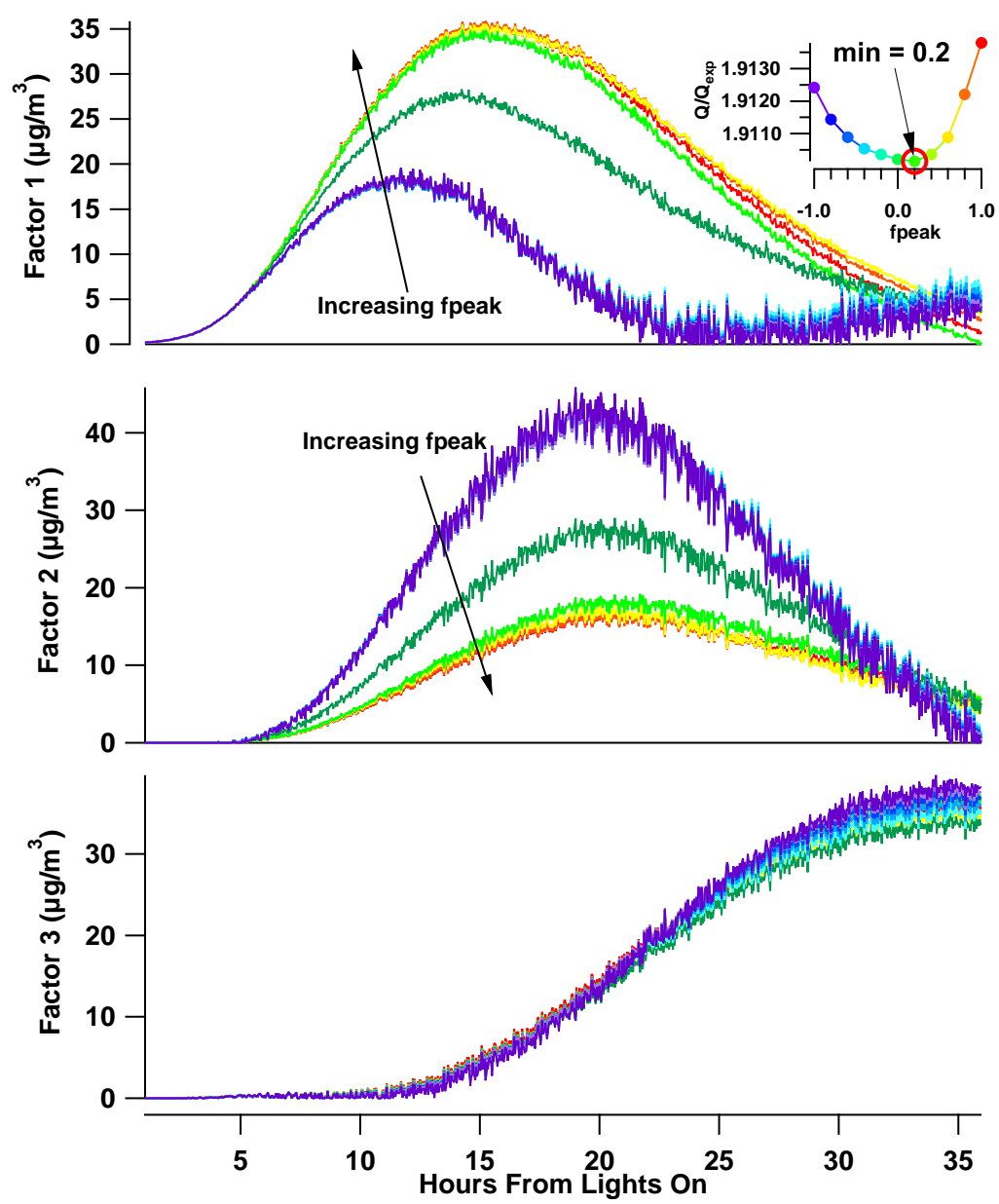

Fig. A7. The change in $f_{\text {peak }}$ affects factors 1 and 2 more than factor 3 . The increase in factor 1 explains the decrease in factor 2 when $f_{\text {peak }}$ changes from 0 to 1 . The same effect occurs when the $f_{\text {peak }}$ changes from 0 to -1 . There is a small change in factor 3 , but overall trend and magnitude remain the same for factor 3 . The minimum in $Q$ is associated with an $f_{\text {peak }}$ of 0.2 .

pattern, whereas for the 3 factor solution (Fig. A6), the pattern is random. This further supports a three factor solution.

The solution was chosen by running several iterations of PMF on the same dataset. As explained by Ulbrich et al. (2009), the PMF solution can be systematically explored by varying $p$, the factor number, and two other parameters, the seeds and the $f_{\text {peaks. }}$. The 3 -factor solution was uniform across many seeds, but not across $f_{\text {peaks. }}$. Figure A7 shows the effect of $f_{\text {peak }}$ for the three factor solution. Factor 3 shows little difference for varying solutions, however factors 1 and 2 seem to trade off mass between the different types of solutions. The minimum of $Q / Q_{\text {expected which oc- }}$ curs at $f_{\text {peak }}=0.2$ (see inset of Fig. A7) was chosen as the solution. This solution had good agreement with the time series comparison with high $m / z$ HR-ToF-AMS molecular ion tracers (Fig. 8) and with the CIMS and MOVI-HRToF-CIMS measurements (Fig. 10). However, as emphasized by Ulbrich et al. (2009), $f_{\text {peak }}$ does not explore all possible rotations (Paatero et al., 2002). In the current experiment, it is possible that factor 1 time trend goes to zero, however, as indicated by the positive $f_{\text {peaks }}$ (Fig. A7), the factor 1 decrease could also taper toward the end of $34 \mathrm{~h}$ and perhaps not reach zero. A longer experiment may have clarified this ambiguity, and/or comparison with aerosol molecular-level information out at this time range. If an external comparison (i.e. MOVI-CIMS molecular trace) for factor 1 did not go to zero, then it would be necessary to pull up the last few elements of the time trend of factor 1 . If the increase in factor 1 at the end of the experiment did not increase $Q$ too intensely, then the desired rotation would have been found (Paatero, 2012). Although not reported here, a full exploration of rotational ambiguity requires induced rotations, such as the example just described, by explicitly pulling individual factor elements in desired directions. For PMF2, this is described in Paatero et al. (2002).

The solution of PMF will only be as descriptive as the data matrix itself. In a chamber experiment, the initial mass spectra reflect the chemistry of early aerosol formation and are not necessarily the same as those later in the oxidation. 


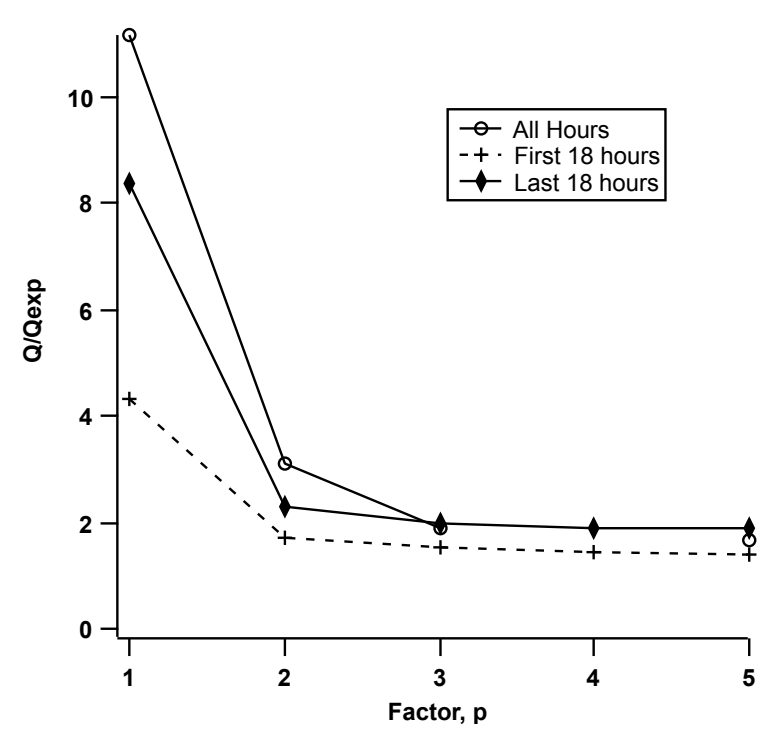

Fig. A8. $Q / Q_{\exp }$ vs. $p$ for 3 types of solutions.

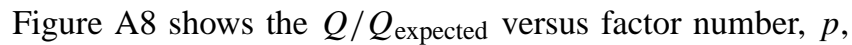
for the 1 seed solution from experiment 2 for "all h", "first $18 \mathrm{~h}$ ", and the "last $18 \mathrm{~h}$ ". For the 1 factor solution $(p=1)$, the "first $18 \mathrm{~h}$ " solution has the lowest $Q / Q_{\text {expected }}$, the "all $\mathrm{h}$ " solution has the highest $Q / Q_{\text {expected, }}$ and the "last $18 \mathrm{~h}$ " is in between. This trend is the same for $p=2$. The first $18 \mathrm{~h}$ solution is lower than the last $18 \mathrm{~h}$ because chemically the mass spectra are less complex at the beginning of the experiment, and $p=1$ or $p=2$ describes much of the data (there is less variability earlier on, in comparison to the full $34 \mathrm{~h}$ solution). As the oxidation progresses, the aerosol composition becomes more complex, as higher $m / z$ oxygen-containing ions appear in the mass spectra, in addition to those observed at initial aerosol growth. For the same $Q / Q_{\text {expected value, the }}$ last $18 \mathrm{~h}$ (and all $\mathrm{h}$ ) requires more factors to describe the data to the same degree as the "first $18 \mathrm{~h}$ ". Three factors best describe the "all h" solution and the "last $18 \mathrm{~h}$ " solution since the third factor grows in at about $18 \mathrm{~h}$. The "first $18 \mathrm{~h}$ " solution, would not "see" this third factor (since it covers only the first $18 \mathrm{~h}$ ), so only 2 factors are necessary to describe the variability in the input data matrix.

Acknowledgements. This work was supported by US Department of Energy grant DE-SC 000 6626. Analysis of the MOVI-HRToFCIMS data is supported by a grant to J. A. T. from the US Department of Energy (DOE-ER65318).

Edited by: M. C. Facchini

\section{References}

Aiken, A. C., DeCarlo, P. F., Kroll, J. H., Worsnop, D. R., Huffman, J. A., Docherty, K. S., Ulbrich, I. M., Mohr, C., Kimmel, J. R., Sueper, D., Sun, Y., Zhang, Q., Trimborn, A., Northway, M., Ziemann, P. J., Canagaratna, M. R., Onasch, T. B., Alfarra, M. R., Prevot, A. S. H., Dommen, J., Duplissy, J., Metzger, A., Baltensperger, U., and Jimenez, J. L.: O/C and OM/OC Ratios of Primary, Secondary, and Ambient Organic Aerosols with HighResolution Time-of-Flight Aerosol Mass Spectrometry, Environ. Sci. Technol., 42, 4478-4485, 2008.

Aiken, A. C., Salcedo, D., Cubison, M. J., Huffman, J. A., DeCarlo, P. F., Ulbrich, I. M., Docherty, K. S., Sueper, D., Kimmel, J. R., Worsnop, D. R., Trimborn, A., Northway, M., Stone, E. A., Schauer, J. J., Volkamer, R. M., Fortner, E., de Foy, B., Wang, J., Laskin, A., Shutthanandan, V., Zheng, J., Zhang, R., Gaffney, J., Marley, N. A., Paredes-Miranda, G., Arnott, W. P., Molina, L. T., Sosa, G., and Jimenez, J. L.: Mexico City aerosol analysis during MILAGRO using high resolution aerosol mass spectrometry at the urban supersite (T0) - Part 1: Fine particle composition and organic source apportionment, Atmos. Chem. Phys., 9, 6633-6653, doi:10.5194/acp-9-6633-2009, 2009.

Allan, J. D.: Quantitative sampling using an Aerodyne aerosol mass spectrometer 1 . Techniques of data interpretation and error analysis, J. Geophys. Res., 108, 4090, doi:10.1029/2002JD002358, 2003.

Allan, J. D., Delia, A. E., Coe, H., Bower, K. N., Alfarra, M. R., Jimenez, J. L., Middlebrook, A. M., Drewnick, F., Onasch, T. B., Canagaratna, M. R., Jayne, J. T., and Worsnop, D. R.: A generalised method for the extraction of chemically resolved mass spectra from Aerodyne aerosol mass spectrometer data, J. Aerosol Sci., 35, 909-922, 2004.

Chhabra, P. S., Flagan, R. C., and Seinfeld, J. H.: Elemental analysis of chamber organic aerosol using an aerodyne high-resolution aerosol mass spectrometer, Atmos. Chem. Phys., 10, 4111-4131, doi:10.5194/acp-10-4111-2010, 2010.

Chhabra, P. S., Ng, N. L., Canagaratna, M. R., Corrigan, A. L., Russell, L. M., Worsnop, D. R., Flagan, R. C., and Seinfeld, J. H.: Elemental composition and oxidation of chamber organic aerosol, Atmos. Chem. Phys., 11, 8827-8845, doi:10.5194/acp-11-88272011, 2011.

Cocker, D. R., Flagan, R. C., and Seinfeld, J. H.: State-of-the-Art Chamber Facility for Studying Atmospheric Aerosol Chemistry, Environ. Sci. Technol., 35, 2594-2601, 2001.

Crounse, J. D., McKinney, K. A., Kwan, A. J., and Wennberg, P. O.: Measurement of Gas-Phase Hydroperoxides by Chemical Ionization Mass Spectrometry, Anal. Chem., 78, 6726-6732, 2006.

DeCarlo, P. F., Kimmel, J. R., Trimborn, A., Northway, M. J., Jayne, J. T., Aiken, A. C., Gonin, M., Fuhrer, K., Horvath, T., Docherty, K. S., Worsnop, D. R., and Jimenez, J. L.: Field-Deployable, High-Resolution, Time-of-Flight Aerosol Mass Spectrometer, Anal. Chem., 78, 8281-8289, 2006.

Fraser, R. T. M., Paul, N. C., and Phillips, L.: Mass spectrometry of some alkyl peroxides, J. Chem. Soc. B, 1970, 1278-1280, doi:10.1039/J29700001278, 1970.

Fry, J. L., Kiendler-Scharr, A., Rollins, A. W., Brauers, T., Brown, S. S., Dorn, H.-P., Dubé, W. P., Fuchs, H., Mensah, A., Rohrer, F., Tillmann, R., Wahner, A., Wooldridge, P. J., and Cohen, R. C.: SOA from limonene: role of $\mathrm{NO}_{3}$ in its generation and degradation, Atmos. Chem. Phys., 11, 3879-3894, doi:10.5194/acp-11- 
3879-2011, 2011.

Heald, C. L., Kroll, J. H., Jimenez, J. L., Docherty, K. S., DeCarlo, P. F., Aiken, A. C., Chen, Q., Martin, S. T., Farmer, D. K., and Artaxo, P.: A simplified description of the evolution of organic aerosol composition in the atmosphere, Geophys. Res. Lett., 37, L08803, doi:10.1029/2010GL042737, 2010.

Hersey, S. P., Craven, J. S., Schilling, K. A., Metcalf, A. R., Sorooshian, A., Chan, M. N., Flagan, R. C., and Seinfeld, J. H.: The Pasadena Aerosol Characterization Observatory (PACO): chemical and physical analysis of the Western Los Angeles basin aerosol, Atmos. Chem. Phys., 11, 7417-7443, doi:10.5194/acp11-7417-2011, 2011.

Isaacman, G., Chan, A. W. H., Nah, T., Worton, D. R., Ruehl, C. R., Wilson, K. R., and Goldstein, A. H.: Heterogeneous $\mathrm{OH}$ Oxidation of Motor Oil Particles Causes Selective Depletion of Branched and Less Cyclic Hydrocarbons, Environ. Sci. Technol., 46, 10632-10640, 2012.

Jimenez, J. L., Canagaratna, M. R., Donahue, N. M., Prévôt, A. S. H., Zhang, Q., Kroll, J. H., DeCarlo, P. F., Allan, J. D., Coe, H., Ng, N. L., Aiken, A. C., Docherty, K. S., Ulbrich, I. M., Grieshop, A. P., Robinson, A. L., Duplissy, J., Smith, J. D., Wilson, K. R., Lanz, V. A., Hueglin, C., Sun, Y. L., Tian, J., Laaksonen, A., Raatikainen, T., Rautiainen, J., Vaattovaara, P., Ehn, M., Kulmala, M., Tomlinson, J. M., Collins, D. R., Cubison, M. J., E., Dunlea, J., Huffman, J. A., Onasch, T. B., Alfarra, M. R., Williams, P. I., Bower, K., Kondo, Y., Schneider, J., Drewnick, F., Borrmann, S., Weimer, S., Demerjian, K., Salcedo, D., Cottrell, L., Griffin, R., Takami, A., Miyoshi, T., Hatakeyama, S., Shimono, A., Sun, J. Y., Zhang, Y. M., Dzepina, K., Kimmel, J. R., Sueper, D., Jayne, J. T., Herndon, S. C., Trimborn, A. M., Williams, L. R., Wood, E. C., Middlebrook, A. M., Kolb, C. E., Baltensperger, U., and Worsnop, D. R.: Evolution of Organic Aerosols in the Atmosphere, Science, 326, 1525-1529, 2009.

Lambe, A. T., Onasch, T. B., Massoli, P., Croasdale, D. R., Wright, J. P., Ahern, A. T., Williams, L. R., Worsnop, D. R., Brune, W. H., and Davidovits, P.: Laboratory studies of the chemical composition and cloud condensation nuclei $(\mathrm{CCN})$ activity of secondary organic aerosol (SOA) and oxidized primary organic aerosol (OPOA), Atmos. Chem. Phys., 11, 8913-8928, doi:10.5194/acp11-8913-2011, 2011.

Lambe, A. T., Onasch, T. B., Croasdale, D. R., Wright, J. P., Martin, A. T., Franklin, J. P., Massoli, P., Kroll, J. H., Canagaratna, M. R., Brune, W. H., Worsnop, D. R., and Davidovits, P.: Transitions from Functionalization to Fragmentation Reactions of Laboratory Secondary Organic Aerosol (SOA) Generated from the OH Oxidation of Alkane Precursors, Environ. Sci. Technol., 46, 5430-5437, 2012.

Lanz, V. A., Alfarra, M. R., Baltensperger, U., Buchmann, B., Hueglin, C., and Prévôt, A. S. H.: Source apportionment of submicron organic aerosols at an urban site by factor analytical modelling of aerosol mass spectra, Atmos. Chem. Phys., 7, 15031522, doi:10.5194/acp-7-1503-2007, 2007.

Loza, C. L., Chhabra, P. S., Yee, L. D., Craven, J. S., Flagan, R. C., and Seinfeld, J. H.: Chemical aging of $m$-xylene secondary organic aerosol: laboratory chamber study, Atmos. Chem. Phys., 12, 151-167, doi:10.5194/acp-12-151-2012, 2012.

Ng, N. L., Canagaratna, M. R., Zhang, Q., Jimenez, J. L., Tian, J., Ulbrich, I. M., Kroll, J. H., Docherty, K. S., Chhabra, P. S., Bahreini, R., Murphy, S. M., Seinfeld, J. H., Hildebrandt,
L., Donahue, N. M., DeCarlo, P. F., Lanz, V. A., Prévôt, A. S. H., Dinar, E., Rudich, Y., and Worsnop, D. R.: Organic aerosol components observed in Northern Hemispheric datasets from Aerosol Mass Spectrometry, Atmos. Chem. Phys., 10, 46254641, doi:10.5194/acp-10-4625-2010, 2010.

Ng, N. L., Canagaratna, M. R., Jimenez, J. L., Chhabra, P. S., Seinfeld, J. H., and Worsnop, D. R.: Changes in organic aerosol composition with aging inferred from aerosol mass spectra, Atmos. Chem. Phys., 11, 6465-6474, doi:10.5194/acp-11-64652011, 2011.

Paatero, P.: Interactive comment on Atmos. Chem. Phys. Discuss., 12, 16647, 2012.

Paatero, P. and Hopke, P. K.: Discarding or downweighting highnoise variables in factor analytic models, Anal. Chim. Acta, 490, 277-289, 2003.

Paatero, P. and Tapper, U.: Positive Matrix Factorization - a Nonnegative Factor Model with Optimal Utilization of ErrorEstimates of Data Values, Environmetrics, 5, 111-126, 1994.

Paatero, P., Hopke, P. K., Song, X. H., and Ramadan, Z.: Understanding and controlling rotations in factor analytic models, Chemometr. Intell. Lab., 60, 253-264, 2002.

Paulot, F., Crounse, J. D., Kjaergaard, H. G., Kroll, J. H., Seinfeld, J. H., and Wennberg, P. O.: Isoprene photooxidation: new insights into the production of acids and organic nitrates, Atmos. Chem. Phys., 9, 1479-1501, doi:10.5194/acp-9-1479-2009, 2009.

Pye, H. O. T. and Pouliot, G. A.: Modeling the Role of Alkanes, Polycyclic Aromatic Hydrocarbons, and Their Oligomers in Secondary Organic Aerosol Formation, Environ. Sci. Technol., 46, 6041-6047, 2012.

Schauer, J. J., Kleeman, M. J., Cass, G. R., and Simoneit, B. R. T. Measurement of Emissions from Air Pollution Sources. 3. C1C29 Organic Compounds from Fireplace Combustion of Wood, Environ. Sci. Technol., 35, 1716-1728, 2001.

Schauer, J. J., Kleeman, M. J., Cass, G. R., and Simoneit, B. R. T.: Measurement of Emissions from Air Pollution Sources. 5. C1C32 Organic Compounds from Gasoline-Powered Motor Vehicles, Environ. Sci. Technol., 36, 1169-1180, 2002.

St. Clair, J. M., McCabe, D. C., Crounse, J. D., Steiner, U., and Wennberg, P. O.: Chemical ionization tandem mass spectrometer for the in situ measurement of methyl hydrogen peroxide, Rev. Sci. Instrum., 81, 094102, doi:10.1063/1.3480552, 2010.

Tobias, H. J. and Ziemann, P. J.: Thermal Desorption Mass Spectrometric Analysis of Organic Aerosol Formed from Reactions of 1-Tetradecene and $\mathrm{O}_{3}$ in the Presence of Alcohols and Carboxylic Acids, Environ. Sci. Technol., 34, 2105-2115, 2000.

Ulbrich, I. M., Canagaratna, M. R., Zhang, Q., Worsnop, D. R., and Jimenez, J. L.: Interpretation of organic components from Positive Matrix Factorization of aerosol mass spectrometric data, Atmos. Chem. Phys., 9, 2891-2918, doi:10.5194/acp-9-2891-2009, 2009.

Van Krevelen, D. W.: Graphical-statistical method for the study of structure and reaction processes of coal, Fuel, 24, 269-284, 1950.

Yatavelli, R. L. N. and Thornton, J. A.: Particulate Organic Matter Detection Using a Micro-Orifice Volatilization Impactor Coupled to a Chemical Ionization Mass Spectrometer (MOVICIMS), Aerosol Sci. Tech., 44, 61-74, 2010.

Yatavelli, R. L. N., Lopez-Hilfiker, F. D., Wargo, J., Kimmel, J. R., Cubison, M. J., Bertram, T. H., Jimenez, J., Gonin, M., Worsnop, D. R., and Thornton, J. A.: Analysis of Gas and Particle-phase 
Organic Matter Using a Chemical Ionization High-Resolution Time-of-Flight Mass Spectrometer (HTOF-CIMS) Coupled to a Micro Orifice Volatilization Impactor (MOVI), Aerosol Sci. Tech., 46, 1313-1327, doi:10.1080/02786826.2012.712236, 2012.

Yee, L. D., Craven, J. S., Loza, C. L., Schilling, K. A., Ng, N. L., Canagaratna, M. R., Ziemann, P. J., Flagan, R. C., and Seinfeld, J. H.: Secondary Organic Aerosol Formation from Low-NO Photooxidation of Dodecane: Evolution of Multi-Generation Gas-Phase Chemistry and Aerosol Composition, J. Phys. Chem. A, 116, 6211-6230, 2012.
Zhang, Q., Jimenez, J. L., Canagaratna, M. R., Ulbrich, I. M., Ng, N. L., Worsnop, D. R., and Sun, Y.: Understanding atmospheric organic aerosols via factor analysis of aerosol mass spectrometry: a review, Anal. Bioanal. Chem., 401, 3045-3067, 2011.

Ziemann, P. J.: Formation of Alkoxyhydroperoxy Aldehydes and Cyclic Peroxyhemiacetals from Reactions of Cyclic Alkenes with $\mathrm{O}_{3}$ in the Presence of Alcohols, J. Phys. Chem. A, 107, 2048-2060, 2003. 